Check for updates

Cite this: Mater. Adv., 2021, 2,2684

Received 30th December 2020, Accepted 2nd March 2021

DOI: 10.1039/d0ma01025a

rsc.li/materials-advances

\title{
Metal-doped carbons from polyurea-crosslinked alginate aerogel beads $\dagger$
}

\author{
Grigorios Raptopoulos, ${ }^{a}$ Maria Papastergiou, ${ }^{a}$ Despoina Chriti, ${ }^{a}$ \\ Eleni Effraimopoulou, ${ }^{a}$ Tomaž Čendak, (D) ${ }^{b}$ Nikolaos Samartzis, (D) C Gregor Mali, (DD b \\ Theophilos Ioannides, ${ }^{c}$ Pavel Gurikov, (D) d Irina Smirnova ${ }^{e}$ and \\ Patrina Paraskevopoulou (iD *a
}

\begin{abstract}
Metal-doped polyurea-crosslinked alginate aerogel beads ( $\mathrm{X}-\mathrm{M}$-alginate; $\mathrm{M}$ : $\mathrm{Ca}, \mathrm{Co}, \mathrm{Ni}, \mathrm{Cu}$ ) were prepared via the reaction of an aromatic triisocyanate (Desmodur RE) with the $-\mathrm{OH}$ groups on the surface of pre-formed $\mathrm{M}$-alginate wet gels, and with adsorbed gelation water. The $\mathrm{X}$ - $\mathrm{M}$-alginate aerogels consisted of $49-63 \%$ polyurea and contained $2-7 \%$ metal ions; they were fibrous macro/meso/ microporous materials with porosities up to $94 \% \mathrm{v} / \mathrm{v}$, and BET surface areas $245-486 \mathrm{~m}^{2} \mathrm{~g}^{-1}$, comparable to those of native $M$-alginate aerogels $\left(258-542 \mathrm{~m}^{2} \mathrm{~g}^{-1}\right.$ ). The pyrolysis of $\mathrm{X}-\mathrm{M}$-alginate aerogels ( $\mathrm{M}$ : Co, $\mathrm{Ni}, \mathrm{Cu}$ ) at $800{ }^{\circ} \mathrm{C}$ yielded carbon aerogels (X-M-C; 33-37\% yield) doped with the corresponding metal (as well as with $\mathrm{Cu}_{2} \mathrm{O}$ in the case of $\mathrm{X}-\mathrm{Cu}-\mathrm{C}$ ), with crystallite sizes of around $22 \mathrm{~nm}$. The $\mathrm{X}-\mathrm{M}-\mathrm{C}$ aerogels retained the general fibrous morphology of their precursor $(X-M$-alginate) aerogels, and while $\mathrm{X}-\mathrm{CO}-\mathrm{C}$ and $\mathrm{X}-\mathrm{Ni}-\mathrm{C}$ appeared similar, the fibrous morphology of $\mathrm{X}-\mathrm{Cu}-\mathrm{C}$ was distinctly different, indicating an effect of the metal on the nanostructure of the corresponding carbon. The porosities of all $X-M-C$ aerogels were in the range of $88-92 \% \mathrm{v} / \mathrm{v}$, including macro-, meso- and micropores. Their BET surface areas were in the range of $426-541 \mathrm{~m}^{2} \mathrm{~g}^{-1}$, of which $208-319 \mathrm{~m}^{2} \mathrm{~g}^{-1}$ was allocated to micropores. In addition to the metals, XPS, Raman and FTIR analyses showed the presence of oxygen and nitrogen functionalities. Carbon in the $\mathrm{X}-\mathrm{M}-\mathrm{C}$ aerogels showed signs of stacking of graphene oxide sheets (14-15 nm), but also a low degree of graphitization and a large number of defects. This work provides a direct, inexpensive method for the preparation of fibrous metal-, oxygen- and nitrogen-doped carbon aerogels with potential for catalytic and electrochemical applications.
\end{abstract}

\section{Introduction}

Aerogels were discovered in the early 1930 s by Kistler $^{1}$ and they are defined as solid colloidal or polymeric networks of nanoparticles expanded throughout their entire volume by a gas. ${ }^{2,3}$ Silica aerogels were the first prepared, followed soon after by other inorganic oxide aerogels, while organic aerogels, based on organic polymers or biopolymers, hybrid organic-inorganic

\footnotetext{
${ }^{a}$ Inorganic Chemistry Laboratory, Department of Chemistry, National and Kapodistrian University of Athens, Panepistimiopolis Zografou 15771, Athens, Greece.E-mail: paraskevopoulou@chem.uoa.gr

${ }^{b}$ National Institute of Chemistry, Hajdrihova 19, 1000 Ljubljana, Slovenia

${ }^{c}$ Foundation for Research \& Technology-Hellas, Institute of Chemical Engineering Sciences (FORTH/ICE-HT), 26504 Patras, Greece

${ }^{d}$ Laboratory for Development and Modelling of Novel Nanoporous Materials, Hamburg University of Technology, Eißendorfer Straße 38, 21073 Hamburg, Germany

${ }^{e}$ Institute of Thermal Separation Processes, Hamburg University of Technology, Eißendorfer Straße 38, 21073 Hamburg, Germany

† Electronic supplementary information (ESI) available. See DOI: 10.1039/ d0ma01025a
}

aerogels, or carbon aerogels, were developed later. ${ }^{4}$ Along with the development of the different classes of aerogels came their exploitation for various applications, taking advantage of the combination of the chemical composition of the materials and their unique properties related to their nanoporous structure, i.e., high surface areas, low thermal conductivities, low dielectric constants, and high acoustic attenuation. The most wide-spread application of aerogels is thermal insulation; ${ }^{5}$ however aerogels have also been used for energy storage, acoustic insulation, dielectrics, adsorption, sensors and actuators, environmental remediation, catalysis, biomedicine, and in the food industry. ${ }^{4}$

Carbon aerogels, in particular, are chemically inert, have a high electrical conductivity, are highly-porous materials (often with a significant portion of microporosity) and have very high specific surface areas. ${ }^{6}$ These properties, in combination with heteroatom functionalities, including nitrogen and oxygen species as well as nano-sized metals that are homogeneously distributed throughout the entire network, make them excellent candidates for several applications, including, but not limited to, 


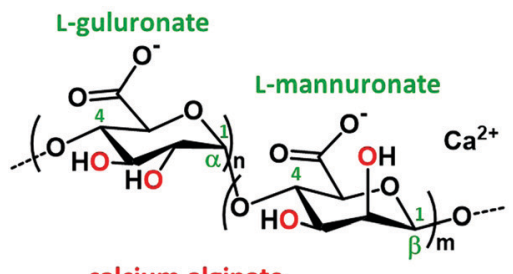

calcium alginate

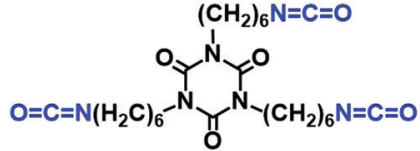

Desmodur N3300

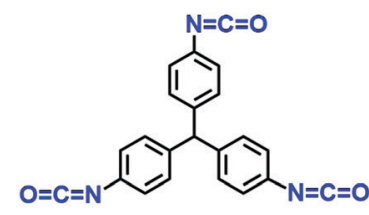

TIPM (Desmodur RE)

Scheme 1 Structures of calcium alginate and of the isocyanates Desmodur N3300 (trimer of hexamethylene diisocyanate) and Desmodur RE (triphenylmethane-4,4', $4^{\prime \prime}$-triisocyanate; TIPM).

electrochemical applications (e.g., double-layer capacitors, electrodes in fuel cells), water desalination, and also for adsorption, heterogeneous catalysis and in biomedical applications. ${ }^{6}$

Carbon aerogels are generally obtained via the pyrolysis of organic aerogels under inert gas $\left(\mathrm{Ar}\right.$ or $\mathrm{N}_{2}$ ). They have been prepared as monoliths, thin films, microspheres or powders. Several organic aerogels have been used as precursors for carbon aerogels, including various phenolic resins, ${ }^{7-9}$ but also polyurea ${ }^{10}$ polyimide, ${ }^{11,12}$ polyamide ${ }^{13,14}$ polyacrylonitrile ${ }^{15}$ aerogels, or bio-based aerogels, such as alginate, ${ }^{16-24}$ cellulose,$^{25}$ chitosan $^{26,27}$ aerogels, and others. In some cases, the addition of carbon nanotubes or graphene oxide to organic sols yields organic polymer/carbon allotrope composite aerogels, which after pyrolysis yield carbon nanotube or graphene aerogels, respectively. ${ }^{19,28-31}$

Recently, we introduced a new class of aerogels, polyureacrosslinked biopolymer (X-alginate and X-chitosan) aerogels, ${ }^{32,33}$ expanding the polymer-crosslinking (X-aerogel) technology that was developed for silica aerogels $s^{34-37}$ and was later applied to a wide range of metal oxide aerogels. ${ }^{38-43}$ In the $\mathrm{X}$-aerogel technology the surface of pre-formed wet-gel networks can be modified, via reaction of the functional groups present on the surface (e.g., $-\mathrm{OH}$ or $-\mathrm{NH}_{2}$ ) with multifunctional reagents (e.g., multifunctional isocyanates), leading to the formation and accumulation of a nano-thin conformal polymer coating over the entire skeletal framework of the inorganic or biopolymer aerogel.

Alginate (Scheme 1) aerogels are carbonizable and advantageous precursors for the preparation of metal-doped aerogels, since they are biopolymers, biocompatible, and can be very easily synthesized in water. ${ }^{44,45}$ It was reasoned that X-alginate aerogels, crosslinked with a polyurea that is also carbonizable, would be good precursors for metal-doped carbon aerogels with higher carbonization yields compared with native alginate aerogels. Besides that, the resulting carbons would be nitrogen-enriched, as the polyurea contains nitrogen. To that end, this study presents a group of $\mathrm{X}-\mathrm{M}$-alginate $(\mathrm{M}: \mathrm{Ca}, \mathrm{Co}, \mathrm{Ni}, \mathrm{Cu}$ ) aerogels, prepared from the corresponding $\mathrm{M}$-alginate wet-gels and the aromatic triisocyanate triphenylmethane-4, $4^{\prime}, 4^{\prime \prime}$-triisocyanate (TIPM; Scheme 1), and their pyrolysis to the corresponding carbon $(\mathrm{X}-\mathrm{M}-\mathrm{C})$ aerogels. The choice of TIPM was based on the fact that all aerogels derived from this triisocyanate, including polyurea, ${ }^{10}$ poly(urethane acrylate) ${ }^{46}$ and polyamide $^{13,14}$ aerogels, are carbonizable, with carbonization yields up to $57 \%$. X-M-C aerogels are not only metal-doped, but they also contain oxygen and nitrogen functional groups, which are highly desirable for electrochemical applications, as they are known to improve surface wettability and conductivity, and sometimes to provide pseudo-capacitance. ${ }^{24}$

\section{Experimental section}

\subsection{Materials and methods}

Two different sodium alginate sources with different guluronic acid (G) contents were used: PROTANAL LF 240 D, G 30-35\% (referred to as G35) and PROTANAL LF $200 \mathrm{~S}$, G 65-75\% (referred to as G75). $\mathrm{CaCl}_{2}, \mathrm{CoCl}_{2} \cdot 6 \mathrm{H}_{2} \mathrm{O}, \mathrm{Ni}\left(\mathrm{NO}_{3}\right)_{2} \cdot 6 \mathrm{H}_{2} \mathrm{O}$ and $\mathrm{CuCl}_{2} \cdot 2 \mathrm{H}_{2} \mathrm{O}$ were purchased from Sigma. Desmodur $\mathrm{RE}(27 \%$ w/w triphenylmethane- $4,4^{\prime}, 4^{\prime \prime}$-triisocyanate (TIPM) solution in ethyl acetate (EA)) was generously provided by Covestro AG. MeCN (HPLC grade) and acetone were purchased from Fisher and were used as received.

SCF drying was carried out in an autoclave (E3100, Quorum Technologies, East Sussex, UK). Wet-gels were placed in the autoclave at $12{ }^{\circ} \mathrm{C}$ and were covered with acetone. Liquid $\mathrm{CO}_{2}$ was added into the autoclave; acetone was drained out as it was being displaced by the liquid $\mathrm{CO}_{2}(5 \times ; 1$ per $30 \mathrm{~min})$. Afterwards, the temperature of the autoclave was raised to $45{ }^{\circ} \mathrm{C}$ and was maintained for $1 \mathrm{~h}$. Finally, the pressure was

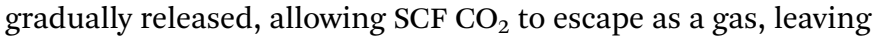
the dry-gels (aerogels).

${ }^{13} \mathrm{C}$ Cross-Polarization Magic Angle Spinning (CPMAS) NMR spectra were obtained using a $600 \mathrm{MHz}$ Varian spectrometer (Varian, Palo Alto, CA, USA) operating at $150.80 \mathrm{MHz}$ for ${ }^{13} \mathrm{C}$. For ${ }^{13} \mathrm{C}$ ramped CPMAS spectra, the spinning rate used was $20 \mathrm{kHz}$. ATR-FTIR spectra were obtained using a PerkinElmer Spectrum 100 Spectrometer. Raman spectra were recorded with the $514.5 \mathrm{~nm}$ laser line, while the scattered light was analyzed using a T64000 micro-Raman spectrometer (Jobin Yvon). A microscope objective of $50 \times$ magnification was used with a spot size of $2-3 \mu \mathrm{m}$. The Raman band of crystalline $\mathrm{Si}$ at $520 \mathrm{~cm}^{-1}$ was used to calibrate the wavenumber scale.

The surface chemistry of the samples was analyzed by means of X-ray Photoelectron Spectroscopy in an ultrahigh vacuum chamber $\left(5 \times 10^{-10}\right.$ mbar $)$ equipped with a SPECS Phoibos 100-1D-DLD hemispherical electron analyzer. XP spectra were acquired using the MgKa $1253.6 \mathrm{eV}$ photon energy and an analyzer pass energy of $10 \mathrm{eV}$, resulting in a full width at half maximum (FWHM) of $0.85 \mathrm{eV}$ for the $\mathrm{Ag} 3 \mathrm{~d}_{5 / 2}$ peak. The diameter of the analyzed area spot was $3 \mathrm{~mm}$, while the atomic ratios were calculated using the intensity (peak area) of the XPS 
peaks weighted with the corresponding relative sensitivity factors (RSF). The RSFs were derived from the Scofield crosssection, taking into account the electron transport properties of the matrix (namely, the inelastic mean free path (IMFP) $\lambda_{i}$ and the elastic-scattering correction factor $Q$ which depend mainly on the corresponding electron kinetic energy (KE)) and the transmission function of the energy analyzer. For the spectral collection and fitting, SpecsLab Prodigy (Specs GmbH, Berlin) commercial software was used. Samples were pressed onto In substrates. For the X-Ni-C sample an AlKa $1486.6 \mathrm{eV}$ photon energy was also employed, so that the In MNN Auger peak does not overlap with the $\mathrm{Ni}_{2} \mathrm{p}_{3 / 2}$ photoemission peak. The binding energy scale was calibrated using the $284.5 \mathrm{eV}$ photoemission peak of $\mathrm{sp}^{2}$ carbon.

Thermogravimetric analysis (TGA) was performed using a Mettler-Toledo TGA/DSC1 instrument (Schwerzenbach, Switzerland). Samples were placed in platinum crucibles. An empty platinum crucible was used as a reference. Samples were heated from ambient temperatures to $800{ }^{\circ} \mathrm{C}$ in a $50 \mathrm{~mL} \mathrm{~min}^{-1}$ flow of $\mathrm{N}_{2}$ at a heating rate of $10{ }^{\circ} \mathrm{C} \mathrm{min}^{-1}$.

$\mathrm{N}_{2}$-sorption and $\mathrm{CO}_{2}$-adsorption measurements were obtained using a Micromeritics Tristar II 3020 surface area and porosity analyzer (Micromeritics, Norcross, GA, USA). Skeletal densities $\left(\rho_{\mathrm{s}}\right)$ were determined by He pycnometry, using a Micromeritics AccuPyc II 1340 pycnometer (Micromeritics, Norcross, GA, USA). Bulk densities $\left(\rho_{\mathrm{b}}\right)$ of the samples were calculated from their weight and natural dimensions.

Scanning electron microscopy (SEM) characterization was conducted with Pt-coated samples adhered to a conductive double-sided adhesive carbon tape, using a high resolution FESEM JEOL JSM 7401f instrument. Scanning electron microscopy (SEM) and energy dispersive X-ray (EDX) spectroscopy experiments were carried out on free-surface, gold-coated dried aerogel filings, adhered on conductive double-sided adhesive carbon tape, using a Jeol JSM 5600 SEM instrument, equipped with an Oxford ISIS 300 micro-analytical device with software ZAF correction quantitative analysis. Examination in the backscattered electron (BSE) mode permitted the localization of bright areas where tungsten was concentrated. The system was operating at $20 \mathrm{kV}, 0.5 \mathrm{nA}$ and $50 \mathrm{sec}$ time of analysis.

Powder X-Ray Diffraction (PXRD) measurements were conducted using a Siemens D5005 instrument with $\mathrm{Cu}$ radiation operating at $40 \mathrm{kV}$ and $40 \mathrm{~mA}$, in the 2-theta range from 3 to $45^{\circ}$, step size $0.01^{\circ} \mathrm{s}^{-1}$ and evaluation was conducted using DIFRAC PLUS v2.2 software from Siemens.

The metal content of the $\mathrm{X}$-M-alginate aerogels was determined by atomic emission spectroscopy (AES) employing a Varian SpectrAA 200 instrument (Varian, Mulgrave, Australia), following wet digestion of the beads with $65 \%$ Suprapur $\mathrm{HNO}_{3}$.

\subsection{Synthesis of $\mathbf{M}$-alginate aerogel beads}

A solution of sodium alginate in $\mathrm{H}_{2} \mathrm{O}(2 \% \mathrm{w} / \mathrm{w})$ was prepared by dissolving sodium alginate (2.00 g; G35 or G75) in $\mathrm{H}_{2} \mathrm{O}$ (98.00 g) at $25{ }^{\circ} \mathrm{C}$. The solution was added dropwise, using a $25 \mathrm{~mL}$ burette, to a $0.2 \mathrm{M}$ solution of a metal salt $\left(\mathrm{CaCl}_{2}, \mathrm{CoCl}_{2} \cdot 6 \mathrm{H}_{2} \mathrm{O}\right.$, $\mathrm{Ni}\left(\mathrm{NO}_{3}\right)_{2} \cdot 6 \mathrm{H}_{2} \mathrm{O}$ or $\left.\mathrm{CuCl}_{2} \cdot 2 \mathrm{H}_{2} \mathrm{O}\right)$ under gentle magnetic stirring.
Spherical hydrogel M-alginate beads were formed instantly and were left to age for $18 \mathrm{~h}$. Afterwards, they were stepwise solventexchanged with acetonitrile/ $\mathrm{H}_{2} \mathrm{O}$ mixtures $(30,60,90 \% \mathrm{v} / \mathrm{v})$, with dry acetonitrile $(4 \times)$, with dry acetone $(3 \times)$, and they were dried with $\mathrm{SCF} \mathrm{CO}_{2}$ to produce the corresponding aerogels (referred to as native $\mathbf{M}$-alginate or $\mathbf{M}$-alg aerogel beads).

\subsection{Synthesis of crosslinked M-alginate aerogel beads}

A solution of the triisocyanate in EA/MeCN was prepared by mixing Desmodur RE (60.0 mL, $16.52 \mathrm{~g}$ TIPM, $0.045 \mathrm{~mol}$ TIPM in EA) with dry MeCN (20 mL). The M-alginate hydrogel beads from Section 2.2 were solvent-exchanged with $\mathrm{MeCN} / \mathrm{H}_{2} \mathrm{O}$ mixtures $(30,60,90 \% \mathrm{v} / \mathrm{v})$ and then with $\mathrm{MeCN}(4 \times)$. Afterwards, they were immersed in a solution of the triisocyanate (the volume of the solution was $4 \times$ the volume of the beads) and they were kept in that solution for $24 \mathrm{~h}$, allowing the triisocyanate to diffuse into the wet-gel beads. Subsequently, the system was transferred into an oven at $70{ }^{\circ} \mathrm{C}$ for $72 \mathrm{~h}$ to accelerate the crosslinking reaction. After that time period, the crosslinked $\mathrm{M}$-alginate wet-gel beads were solvent-exchanged with acetone $(3 \times)$ and were dried with $\mathrm{SCF} \mathrm{CO}_{2}$ to produce the corresponding crosslinked aerogels (referred to as $\mathrm{X}-\mathrm{M}$-alginate or $\mathrm{X}-\mathrm{M}$-alg aerogel beads).

\subsection{Pyrolysis of crosslinked $\mathrm{M}$-alginate (X-M-alginate) aerogel beads}

The $\mathrm{X}-\mathrm{M}$-alginate aerogel beads were transferred into an MTI GSL1600X-80 tube furnace (MTI Corporation, Richmond, CA, USA) (alumina $99.8 \%$ pure, $72 / 80 \mathrm{~mm}$ inner/outer diameters, $457 \mathrm{~mm}$ heating zone). The temperature was raised to $800{ }^{\circ} \mathrm{C}$ at $2.5{ }^{\circ} \mathrm{C} \mathrm{min}{ }^{-1}$ under flowing $\operatorname{Ar}\left(150 \mathrm{~mL} \mathrm{~min}^{-1}\right)$ for $5 \mathrm{~h}$. Afterwards, the temperature was returned to room temperature at $2.5{ }^{\circ} \mathrm{C} \mathrm{min}^{-1}$ under constant flow of $\operatorname{Ar}\left(150 \mathrm{~mL} \mathrm{~min}^{-1}\right)$. After pyrolysis the corresponding carbon aerogels were obtained (referred to as $\mathrm{X}-\mathrm{M}-\mathrm{C}$ aerogel beads).

\section{Results and discussion}

\subsection{Preparation of crosslinked $\mathrm{M}$-alginate (X-M-alginate) aerogel beads}

The M-alginate ( $\mathrm{M}$ : $\mathrm{Ca}, \mathrm{Co}, \mathrm{Ni}, \mathrm{Cu}$ ) wet-gels of this study were crosslinked with TIPM (Desmodur RE), to provide materials with an aromatic polyurea (PUA) coating that is carbonizable. ${ }^{10}$ Crosslinking of the M-alginate beads with TIPM (Desmodur $\mathrm{RE}$ ) was studied for both G35 and G75 sodium alginate gelled by $\mathrm{Ca}^{2+}$ ions, for $\mathrm{G} 35$ alginate gelled by $\mathrm{Cu}^{2+}$ ions, and for $\mathrm{G} 75$ alginate gelled by $\mathrm{Co}^{2+}$ and $\mathrm{Ni}^{2+}$ ions. Co- and $\mathrm{Ni}-$ alginate hydrogel beads derived from G35 alginate suffered severe shrinkage during solvent-exchange with MeCN, even though the solvent exchange from water to MeCN was gradual. Hence, the crosslinking of those samples with TIPM was not studied. On the other hand, the reaction of Cu-containing G75 alginate with TIPM was attempted, but purification of the crosslinked beads was not possible even after numerous washings. Therefore, those materials were not studied further. 


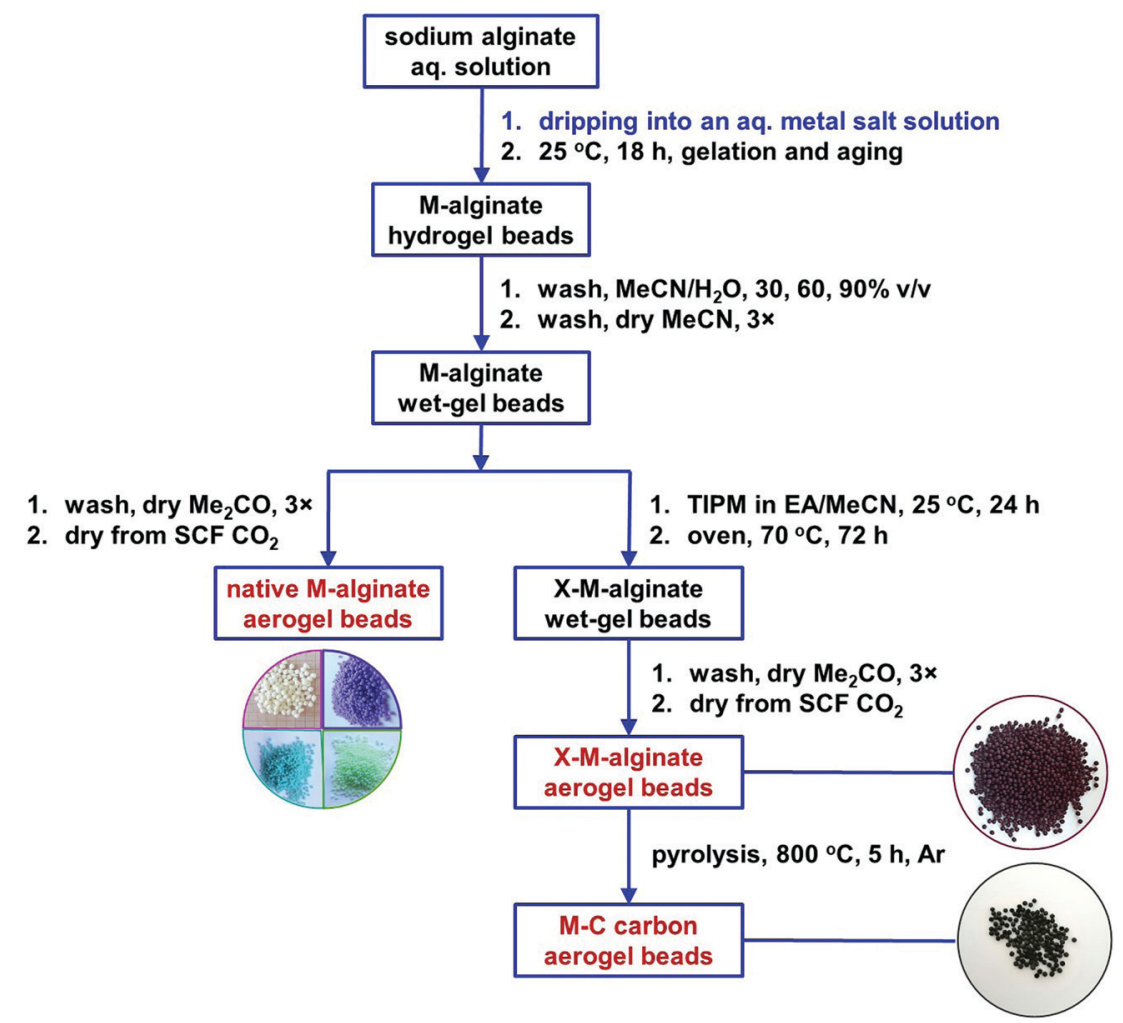

Scheme 2 Synthesis of native ( $M$-alginate), crosslinked ( $X-M$-alginate) and carbon ( $X-M-C ; M: C a, C o, N i, C u$ ) wet-gel and aerogel beads.

The synthetic protocol for the preparation of $\mathrm{M}$-alginate (M: $\mathrm{Ca}, \mathrm{Co}, \mathrm{Ni}, \mathrm{Cu}$ ) hydrogel and aerogel beads is presented in Scheme 2. The M-alginate hydrogel beads were prepared by the dropwise addition of an aqueous sodium alginate solution into an aqueous metal salt solution. Gelation was observed immediately. More specifically, the mechanism of gelation is the same for all metals studied and involves immediate reaction of the sodium alginate containing water droplets with the metal ions in the aqueous receiving solution. This reaction forms a solid porous crust around the droplets, so the internal solution of those droplets does not get dispersed in the receiving solution. Gelation inside the solid droplets is completed as more metal ions diffuse in from the surrounding solution and coordinate to the carboxylate groups of the alginate that is dissolved within the droplets. ${ }^{47}$ This method of gelation, namely inducing phase separation by slow mixing of one phase with another, dates back to the 1930s and in fact was used for the preparation of aerogels by their inventor, Kistler himself. ${ }^{48}$
The beads were aged in the metal salt solution for $18 \mathrm{~h}$, and then they were either processed to the corresponding native $\mathrm{M}$-alginate aerogels, or they were crosslinked with Desmodur RE (TIPM; Scheme 1) to produce the corresponding crosslinked aerogels (X-M-alginate aerogels), according to well-established procedures. $^{32,33}$ In brief, M-alginate wet-gel beads were first solvent-exchanged with acetonitrile, and then they were immersed in a solution of the triisocyanate for $24 \mathrm{~h}$, so that the triisocyanate was diffused into the wet-gels. Next, they were kept in an oven at $70{ }^{\circ} \mathrm{C}$ for $72 \mathrm{~h}$ for the crosslinking reaction to be completed. Representative optical photographs of the $\mathrm{X}-\mathrm{M}$-alginate aerogel beads are shown in Scheme 2. Optical photographs, mean diameters and size distributions of the $\mathrm{M}$-alginate and $\mathrm{X}-\mathrm{M}-$ alginate aerogel beads are shown in Fig. S1 and S2 (ESI $\dagger$ ). Native $\mathrm{M}$-alginate aerogel beads were smaller than those of $\mathrm{X}-\mathrm{M}$-alginate aerogel beads due to higher shrinkage during the solvent exchange and SCF drying. This higher shrinkage is also reflected in the bulk densities of those materials (see Section 3.3 below).

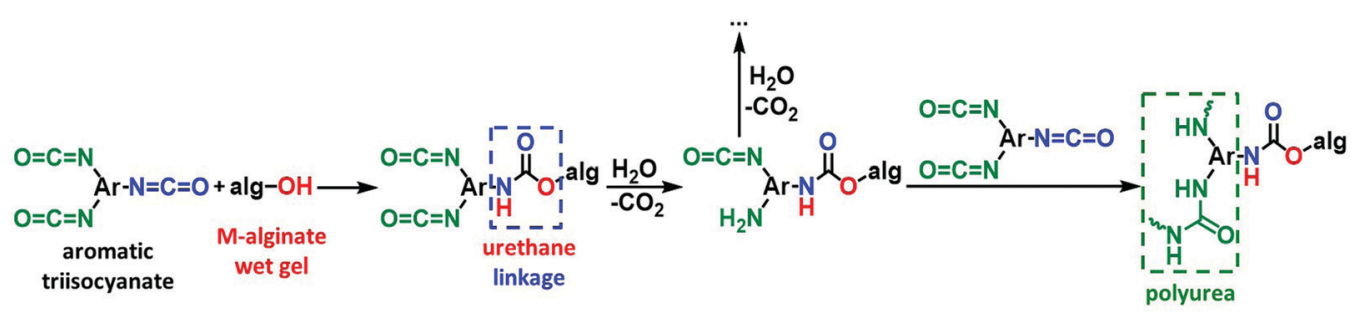

Scheme 3 The reaction of crosslinking $\mathrm{M}$-alginate $(\mathrm{M}: \mathrm{Ca}, \mathrm{Co}, \mathrm{Ni}, \mathrm{Cu}$ ) wet gels with an aromatic triisocyanate. 


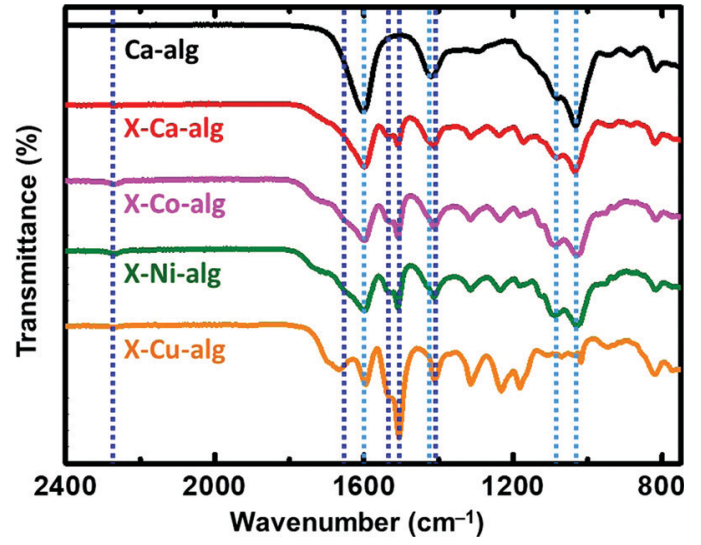

Fig. 1 ATR-FTIR spectra of native ( $\mathrm{Ca}$-alg) and crosslinked (X-M-alg) aerogel beads ( $M$ : $\mathrm{Ca}, \mathrm{Co}, \mathrm{Ni}, \mathrm{Cu}$ ), as indicated. Dashed lines show the positions of the characteristic peaks for $\mathrm{Ca}$-alg (light blue) and $\mathrm{X}-\mathrm{M}$-alg (dark blue) aerogels as discussed in the text.

The crosslinking reaction is shown in Scheme 3. As has recently been described in the literature, ${ }^{32,33}$ the triisocyanate is being "attached" to the alginate backbone through urethane linkages that are formed from the reaction of the $-\mathrm{OH}$ groups of the alginate with one of the - NCO groups of the triisocyanate. The remaining -NCO groups of the triisocyanate are hydrolyzed by water adsorbed on the surface of the alginate wet-gel network and form amines, which react with free triisocyanate in the pores and form urea groups. Hydrolysis of the new dangling -NCO groups continues, followed by reaction with new triisocyanate molecules, until the alginate network is coated with PUA. Some unreacted -NCO groups are detected (by ATR-FTIR presented in Section 3.2 below) in the $\mathrm{X}-\mathrm{M}$-alginate aerogels.
Unreacted -NCO groups were not observed in $\mathrm{X}-\mathrm{Ca}$-alginate aerogels crosslinked with the aliphatic triisocyanate Desmodur N3300. ${ }^{32,33}$ That can be attributed to the relative flexibility of the two polymers: the one based on the flexible/aliphatic Desmodur N3300 (Scheme 1) vs. the one based on the rigid/ aromatic Desmodur RE (TIPM; Scheme 1).

\subsection{Chemical characterization of crosslinked $\mathbf{M}$-alginate (X-M-alginate) aerogel beads}

Native $\mathbf{M}$-alginate and $\mathrm{X}-\mathrm{M}$-alginate aerogels were chemically characterized by ATR-FTIR (Fig. 1), ${ }^{13} \mathrm{C}$ CPMAS (Fig. 2), TGA (Fig. 3), atomic emission spectroscopy (Table 1) and EDX analyses (Fig. S3, ESI $\dagger$ ).

ATR-FTIR spectra of the X-M-alginate aerogels are shown in Fig. 1. A representative spectrum of a native $\mathrm{M}$-alginate aerogel (of a Ca-alginate aerogel) is also shown for comparison. In agreement with the literature,$^{32,33,49-51}$ the spectra of both native and $\mathrm{X}$-alginate aerogels show the characteristic symmetric and asymmetric stretching vibrations of the carboxylate groups coordinated to $\mathrm{Ca}^{2+}$ ions around $1600 \mathrm{~cm}^{-1}$ and $1420 \mathrm{~cm}^{-1}$, respectively, and the corresponding stretching vibrations of the $\mathrm{C}-\mathrm{O}-\mathrm{C}$ groups on the sugar ring around $1080 \mathrm{~cm}^{-1}$ and $1030 \mathrm{~cm}^{-1}$. The spectra of the $\mathrm{X}-\mathrm{M}$-alginate aerogels, in addition to the above, show all of the characteristic peaks expected for PUA derived from Desmodur RE, ${ }^{10,52}$ that is the stretching vibration of the carbonyl of the urea group between 1660 and $1650 \mathrm{~cm}^{-1}$ (in some cases this appears as a shoulder), the scissoring vibration of the $\mathrm{N}-\mathrm{H}$ group around $1530 \mathrm{~cm}^{-1}$, and the stretching vibrations of the aromatic double bonds at 1506 and $1410 \mathrm{~cm}^{-1}$. Small peaks around $2270 \mathrm{~cm}^{-1}$, assigned to the antisymmetric stretching vibration of the $-\mathrm{NCO}$

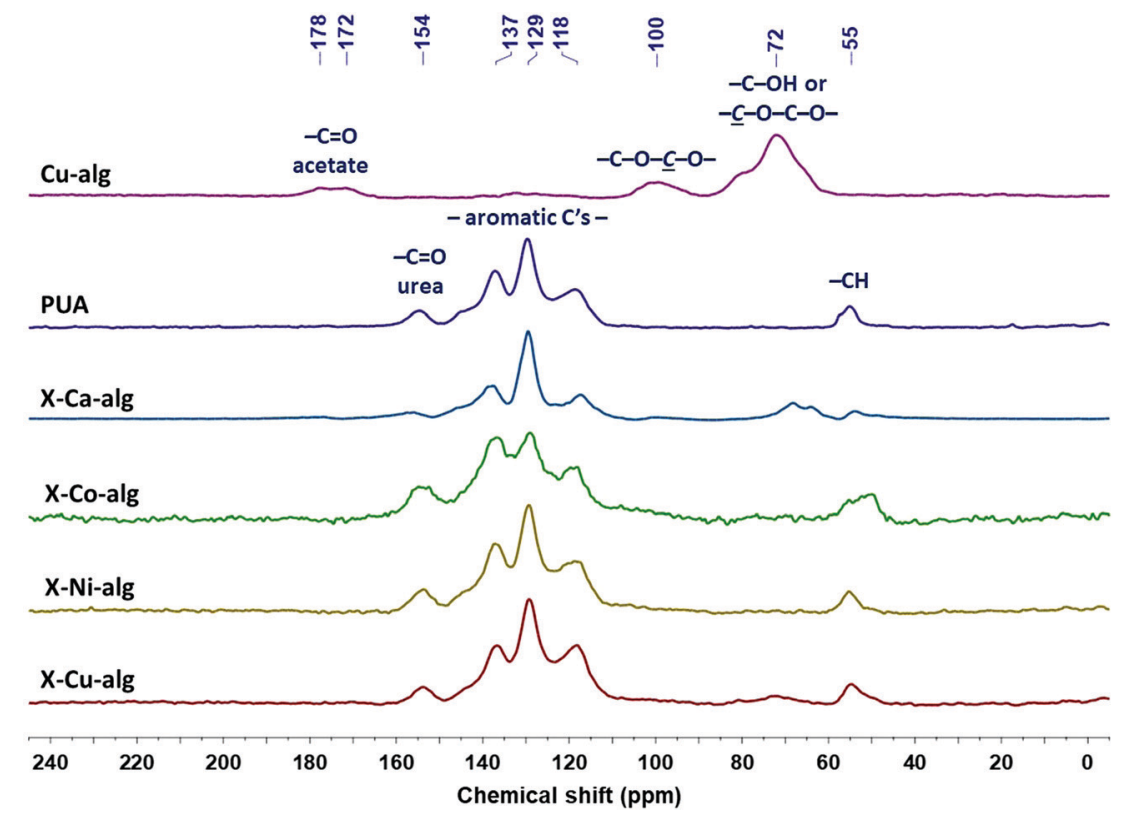

Fig. $2{ }^{13}$ C CPMAS NMR spectra of native (Cu-alg) aerogel beads, of Desmodur RE-derived PUA, and of crosslinked (X-M-alg) aerogel beads (M: Ca, Co, $\mathrm{Ni}, \mathrm{Cu})$, as indicated. 

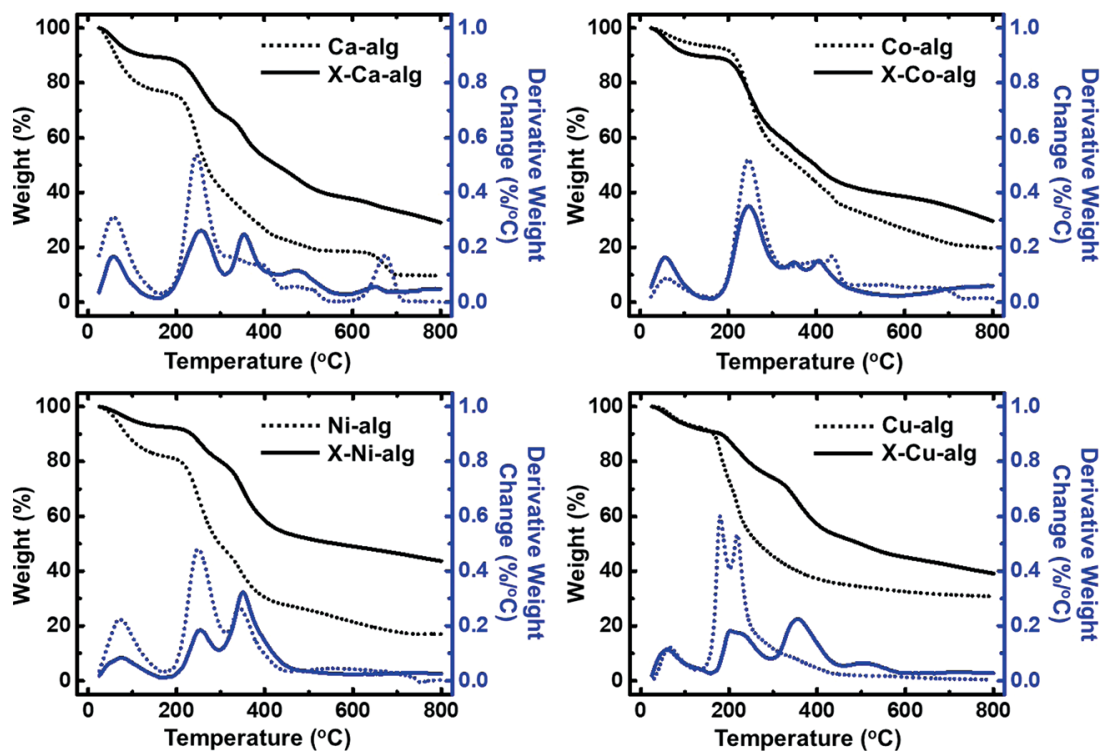

Fig. 3 Thermogravimetric analysis (TGA, under Ar) and differential thermogravimetric analysis (DTG) of native (M-alg - dotted lines) and crosslinked $(\mathrm{X}-\mathrm{M}$-alg - solid lines) aerogel beads $(\mathrm{M}: \mathrm{Ca}, \mathrm{Co}, \mathrm{Ni}, \mathrm{Cu})$, as indicated.

Table 1 Metal (M) content and polyurea (PUA) content of crosslinked (X-M-alg; $\mathrm{M}$ : $\mathrm{Ca}, \mathrm{Co}, \mathrm{Ni}, \mathrm{Cu}$ ) aerogel beads

\begin{tabular}{|c|c|c|c|}
\hline \multirow[b]{2}{*}{ Sample ${ }^{a}$} & \multicolumn{2}{|c|}{ M content ${ }^{b}(\%)$} & \multirow[b]{2}{*}{ PUA content ${ }^{d}(\%)$} \\
\hline & $\mathbf{M}^{c}$ & $\mathrm{Na}$ & \\
\hline X-Ca-alg (G35) & 2.0 & 0.05 & 61 \\
\hline X-Ca-alg (G75) & 1.8 & 0.04 & 55 \\
\hline X-Co-alg (G75) & 7.1 & 0.09 & 49 \\
\hline $\mathrm{X}-\mathrm{Ni}-\mathrm{alg}(\mathrm{G} 75)$ & 3.6 & 0.06 & 61 \\
\hline $\mathrm{X}-\mathrm{Cu}-\mathrm{alg}$ (G35) & 3.7 & 0.04 & 63 \\
\hline \multicolumn{4}{|c|}{ 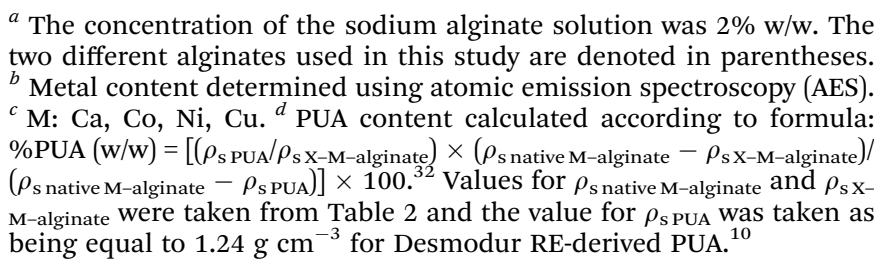 } \\
\hline
\end{tabular}

group, are seen in almost all cases, showing that some of the -NCO groups of the aromatic triisocyanate have not reacted.

The ${ }^{13} \mathrm{C}$ CPMAS NMR spectra of the $\mathrm{X}-\mathrm{M}$-alginate aerogel beads are shown in Fig. 2 along with the spectra of native $\mathrm{Cu}$-alginate and Desmodur RE-derived PUA for comparison purposes. The spectrum of the $\mathrm{Cu}$-alginate aerogel beads is similar to the spectrum of the Ca-alginate aerogel beads, ${ }^{33}$ the only difference being the peak of the acetate carbonyls centered at $176 \mathrm{ppm}$, which is a doublet in the $\mathrm{Cu}$-alginate spectrum. The peaks of the acetal carbons $-\mathrm{C}-\mathrm{O}-\underline{C}-\mathrm{O}-$ on the alginate rings and of the alginate ring carbons attached to oxygen $(-\mathrm{OH}$ or ether) appear at 100 and $72 \mathrm{ppm}$, respectively, as expected. The CPMAS NMR spectra of the Co-alginate and Ni-alginate aerogels could not be recorded because nuclear-spin relaxation was too fast to allow efficient cross polarization; the reason for the accelerated relaxation is in the closeness of the ${ }^{1} \mathrm{H}$ and ${ }^{13} \mathrm{C}$ nuclei to the paramagnetic centers of $\mathrm{Co}^{2+}$ and $\mathrm{Ni}^{2+}$ ions.
The corresponding $\mathrm{X}-\mathrm{M}$-alginate aerogels showed analogous behavior during the solid-state NMR experiments. Although spectra could be recorded for all five $\mathrm{X}-\mathrm{M}$-alginate aerogels ( $\mathrm{M}$ : $\mathrm{Ca}, \mathrm{Co}, \mathrm{Ni}, \mathrm{Cu}$ ), the spectra of $\mathrm{X}-\mathrm{Co}-$ alginate and $\mathrm{X}-\mathrm{Ni}-$ alginate aerogels do not show any of the characteristic peaks of the alginate backbone, but only the peaks of the aromatic PUA formed after the crosslinking reaction, which also predominate in the spectra of $\mathrm{X}-\mathrm{Ca}$-alginate and $\mathrm{X}-\mathrm{Cu}$-alginate. (Again, the signals of the backbone are missing because of the proximity of the corresponding ${ }^{13} \mathrm{C}$ nuclei to the paramagnetic centers.) The peaks of the aromatic PUA appear at $154 \mathrm{ppm}$ (urea $-\mathrm{C}=\mathrm{O}$ ) 137, 129 and $118 \mathrm{ppm}$ (aromatic carbons) and $55 \mathrm{ppm}(-\mathrm{CH}){ }^{10,52}$ Peaks corresponding to the urethane carbonyl (observed as a shoulder at $157 \mathrm{ppm}$ in the spectra of X-Ca-alginate crosslinked with Desmodur N3300) 32,33 $^{3}$ are not visible, reflecting the fact that the amount of urethane groups is small, as those are only the links of PUA to the alginate framework. Peaks corresponding to the -NCO groups (an expected peak around $120 \mathrm{ppm}$ ) are not visible either, because of the small amount of unreacted -NCO groups and because of the overlap with the peak at $118 \mathrm{ppm}$.

Thermal characterization (Fig. 3) of the native M-alginate aerogels showed three pyrolysis regions: the first one is below $150{ }^{\circ} \mathrm{C}$, the second one is between $150{ }^{\circ} \mathrm{C}$ and $500{ }^{\circ} \mathrm{C}$, and the third one is above $500{ }^{\circ} \mathrm{C}$. The first region can be attributed to loss of water. The second region, where the major weight loss was observed, is attributed to degradation of the polymer chain. The third region is where a slower degradation was observed, corresponding to the lowest weight loss. It has been reported in the literature that in this region (and maybe as early as at $300{ }^{\circ} \mathrm{C}$ ) secondary pyrolytic reactions, such as tar cracking, char formation, and/or degradation of thermally robust inorganic components, may take place. ${ }^{53}$ The thermal stability and the decomposition of $\mathbf{M}$-alginate aerogels of this study follow the 
Table 2 Selected material properties of native (M-alg) and crosslinked ( $\mathrm{X}-\mathrm{M}$-alg) aerogel beads (M: Ca, Co, Ni, Cu)

\begin{tabular}{|c|c|c|c|c|c|c|c|}
\hline Sample ${ }^{a}$ & $\begin{array}{l}\text { Bulk } \\
\text { density } \\
\rho_{\mathrm{b}}\left(\mathrm{g} \mathrm{cm}^{-3}\right)\end{array}$ & $\begin{array}{l}\text { Skeletal } \\
\text { density } \\
\rho_{\mathrm{s}}\left(\mathrm{g} \mathrm{cm}^{-3}\right)\end{array}$ & $\begin{array}{l}\text { Porosity } \\
\Pi(\% \mathrm{v} / \mathrm{v})\end{array}$ & $\begin{array}{l}\text { BET surf. } \\
\text { area } \\
\sigma\left(\mathrm{m}^{2} \mathrm{~g}^{-1}\right) \\
\text { [micropore } \\
\text { surf. area] }{ }^{c}\end{array}$ & $\begin{array}{l}V_{\text {Total }}{ }^{d} \\
\left(V_{1.7-300 \mathrm{~nm}}\right)^{e} \\
\left(\mathrm{~cm}^{3} \mathrm{~g}^{-1}\right)\end{array}$ & $\begin{array}{l}\text { Av. pore } \\
\text { diam }{ }^{f} \\
\left(4 V_{\text {Total }} / \sigma\right) \\
(\mathrm{nm})\end{array}$ & $\begin{array}{l}\text { Particle } \\
\text { radius }^{g} \\
\text { (nm) }\end{array}$ \\
\hline Ca-alg $(\mathrm{G} 35)^{33}$ & $0.072 \pm 0.001$ & $2.07 \pm 0.02$ & 97 & 304 [67] & $13(0.5)$ & $7.9(176)$ & $5.7(6.1)$ \\
\hline $\mathrm{X}-\mathrm{Ca}-\mathrm{alg}$ (G35) & $0.133 \pm 0.001$ & $1.468 \pm 0.004$ & 91 & $296[20]$ & $6.8(0.6)$ & $8.8(92)$ & $6.9(7.4)$ \\
\hline $\mathrm{Ca}-\mathrm{alg}(\mathrm{G} 75)^{33}$ & $0.148 \pm 0.001$ & $1.934 \pm 0.006$ & 92 & 542 [83] & $6.2(4.9)$ & $36(46)$ & $2.9(3.4)$ \\
\hline Ni-alg (G75) & $0.172 \pm 0.001$ & $1.98 \pm 0.01$ & 91 & $393[58]$ & $5.3(1.2)$ & $13(54)$ & $3.9(4.5)$ \\
\hline $\mathrm{X}-\mathrm{Ni}-\mathrm{alg}$ (G75) & $0.16 \pm 0.01$ & $1.449 \pm 0.004$ & 89 & $276[27]$ & $5.6(0.9)$ & $15(81)$ & $7.5(8.3)$ \\
\hline $\mathrm{Cu}-\mathrm{alg}$ (G35) & $0.10 \pm 0.01$ & $2.00 \pm 0.03$ & 95 & $408[73]$ & $9.2(1.6)$ & $16(90)$ & $3.7(4.5)$ \\
\hline $\mathrm{X}-\mathrm{Cu}-\mathrm{alg}$ (G35) & $0.096 \pm 0.007$ & $1.44 \pm 0.02$ & 93 & $331[22]$ & $9.7(1.2)$ & 15 (118) & $6.3(6.7)$ \\
\hline
\end{tabular}

${ }^{a}$ The concentration of the sodium alginate solution was $2 \% \mathrm{w} / \mathrm{w}$. The two different alginates used in this study are denoted in parentheses. ${ }^{b}$ Porosity calculated according to the formula: $\left(\rho_{\mathrm{s}}-\rho_{\mathrm{b}}\right) / \rho_{\mathrm{s}}$, where $\rho_{\mathrm{s}}$ : skeletal density and $\rho_{\mathrm{b}}$ : bulk density. ${ }^{c}$ Micropore surface area via $t$-plot analysis, according to the Harkins and Jura model. ${ }^{d}$ Total pore volume calculated according to the formula: $1 / \rho_{\mathrm{b}}-1 / \rho_{\mathrm{s}}{ }^{e}{ }^{e}$ Cumulative volume of pores between 1.7 and $300 \mathrm{~nm}$ from $\mathrm{N}_{2}$-sorption data and the BJH desorption method. ${ }^{f}$ Calculated using the $4 V / \sigma$ method; $V$ was set equal to the maximum volume of $\mathrm{N}_{2}$ adsorbed along the isotherm as $P / P_{\mathrm{o}} \rightarrow 1.0$. For the number in parentheses, $V$ was set equal to $V_{\text {Total }}$ from the previous column. ${ }^{g}$ Particle radius calculated using the formula: $r=3 /\left(\rho_{\mathrm{s}} \times \sigma\right)$, where $\sigma$ : BET surface area. For the number in parentheses, $\sigma$ was set equal to the external surface area, $\sigma_{\text {ext }}$, calculated from the BET surface area minus the micropore surface area.

general trends that have been reported in the literature for M-alginate materials, keeping in mind that the thermal stability of the alginate materials depends on both the alginate source (as alginates are natural materials), and on the metal cation. ${ }^{53-55}$ The thermal decomposition of $\mathrm{X}-\mathrm{M}$-alginate aerogels followed more or less the same trend, but they have a higher residue at $800{ }^{\circ} \mathrm{C}$ (around $30 \%$ for $\mathrm{M}$ : $\mathrm{Ca}$ and Co and around $40 \%$ for $\mathrm{M}: \mathrm{Ni}$ and $\mathrm{Cu}$ ), compared with the residue of native aerogels (in the range of 10 to $30 \%$ ). That high residue for the $\mathrm{X}-\mathrm{M}$-alginate aerogels is due to the aromatic PUA and has been observed for all Desmodur RE-derived aerogels in the literature. ${ }^{10,13,46,52,56-58}$ Therefore, these materials are very good candidates for pyrolysis and conversion to the corresponding carbons (see Section 3.4 below).

To complete the chemical characterization of the new materials, atomic emission spectroscopy has been used to calculate the metal content of $\mathrm{X}-\mathrm{M}$-alginate aerogels. The results are presented in Table 1. The metal content was in the range of 1.8 to $7.1 \% \mathrm{w} / \mathrm{w}$, with $\mathrm{X}$-Co-alginate aerogels having the highest metal content per weight. It is also noted that the moles of $\mathrm{M}$ in $100 \mathrm{~g}$ of X-Nialginate and $\mathrm{X}-\mathrm{Cu}$-alginate aerogels were about the same (0.05$0.06 \mathrm{~mol}$ ) while in $\mathrm{X}$-Co-alginate the moles of $\mathrm{Co}$ were about double than the other two cases $(0.12 \mathrm{~mol})$. The Na residue (from sodium alginate) is lower than $0.1 \%$ in all aerogels. The very low $\mathrm{Na}$ residue is confirmed with EDX spectra (Fig. S3, ESI $\dagger$ ), in which no Na peaks are observed. Table 1 also shows the PUA content, which has been calculated from the skeletal densities reported in Table 2 and which has been found to be in the range of $49-61 \%$ (Table 1).

\subsection{Material properties of crosslinked M-alginate (X-M-alginate) aerogel beads}

All aerogels (native and crosslinked) were characterized with $\mathrm{N}_{2}$-sorption porosimetry, helium pycnometry and SEM. The selected material properties of all aerogels are summarized in Table 2. In general, the aerogels of this study have low bulk densities. Unlike the $\mathrm{X}$-Ca-alginate aerogels studied before, ${ }^{32,33}$ of which the bulk density was always higher compared with the bulk density of the corresponding native aerogels, in the present study there is no clear trend. For example, $\mathrm{X}-\mathrm{Ni}$-alginate and $\mathrm{X}-\mathrm{Cu}$-alginate aerogel beads have almost the same bulk densities with the corresponding native aerogels. That finding can be explained because native aerogel beads exhibit higher shrinkage during solventexchange and SCF drying, and because of the rigid core of TIPM that provides more open structures. It can be further supported by the fact that $\mathrm{X}-\mathrm{Ca}$-alginate aerogel beads crosslinked with Desmodur $\mathrm{N}_{3} 300^{33}$ have higher bulk densities compared with those crosslinked with Desmodur RE (0.157 $\mathrm{g} \mathrm{cm}^{-3}$ vs. $0.146 \mathrm{~g} \mathrm{~cm}^{-3}$ for G75-derived materials), although they were both prepared from sodium alginate solutions of the same concentration $(2 \% \mathrm{w} / \mathrm{w})$ and have the same PUA content ( $53 \%$ vs. $55 \%)$. Skeletal densities are consistently lower for X-M-alginate aerogel beads compared with the corresponding native aerogels.

All aerogels are highly porous, with porosities up to $97 \% \mathrm{v} / \mathrm{v}$ for the native $\mathrm{M}$-alginate aerogels and $94 \% \mathrm{v} / \mathrm{v}$ for $\mathrm{X}-\mathrm{M}-$ alginate aerogels (Table 2). Although the porosities are compromised a little during crosslinking, they still remain very high. All aerogels are mostly macroporous materials $\left(V_{\text {Total }}>\right.$ $\left.V_{1.7-300 \mathrm{~nm}}\right)$, and all show some microporosity, although the portion of the surface area that is assigned to micropores is lower for the $\mathrm{X}-\mathrm{M}$-alginate aerogels compared with the corresponding native aerogels. The fact that the $\mathrm{X}-\mathrm{M}$-alginate aerogels have microporosity is attributed to the rigid aromatic core of TIPM: all aerogels that have been reported from TIPM (Desmodur RE), including polyurea, ${ }^{10,52}$ polyurethane, ${ }^{57}$ poly(urethane norbornene), ${ }^{56,58}$ poly(urethane acrylate), ${ }^{46,58}$ and polyamide ${ }^{13,14}$ aerogels, have small amounts of microporosity. On the other hand, $\mathrm{X}-\mathrm{Ca}$-alginate aerogels from Desmodur N3300 that have been reported previously ${ }^{32,33}$ were 

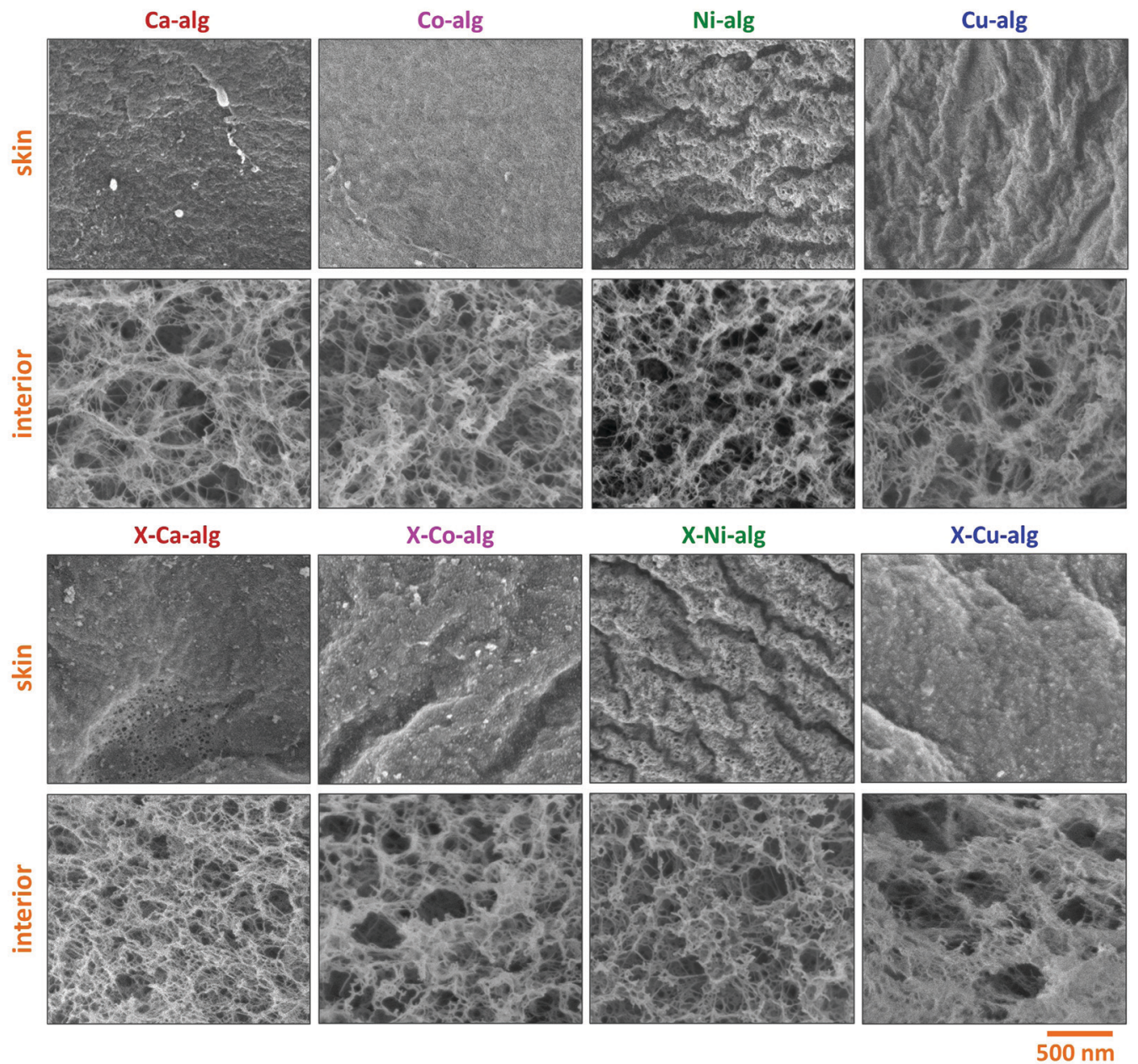

Fig. 4 Representative SEM images of native ( $M$-alg) and crosslinked $(X-M$-alg) aerogel beads ( $M$ : Ca, Co, Ni, Cu), as indicated. SEM images of native $\mathrm{Ca}$-alginate beads have also been reported in ref. 33 .

also macroporous materials and they had no microporosity. Finally, the plot of $1 / \rho_{\mathrm{b}}$ vs. $V_{\text {Total }}$ is linear for both native M-alginate and X-M-alginate aerogels (Fig. S5, ESI $\dagger$ ), which strongly suggests that there is no closed porosity.

The $\mathrm{N}_{2}$-sorption isotherms (Fig. S4, ESI $\dagger$ ) have a small loop and do not reach saturation, also indicating macroporous materials with some mesoporosity. The Barrett-JoynerHalenda (BJH) curves (Fig. S4, ESI $\dagger$ ), for pores in the range of 1.7-300 nm, showed maxima in the range of $27-34 \mathrm{~nm}$ for native materials and in the range of $32-44 \mathrm{~nm}$ for crosslinked materials, together with broad distributions, as expected for networks formed after particle aggregation. BET surface areas (Table 2) were still high (245-486 $\mathrm{m}^{2} \mathrm{~g}^{-1}$ ), and were not much lower compared with the native aerogels $\left(258-542 \mathrm{~m}^{2} \mathrm{~g}^{-1}\right)$. The average pore sizes did not change significantly after crosslinking, either, while the size of the primary particles increased a little (from 2.9-6.1 nm to 4.2-8.1 nm). The above observations are consistent with PUA formation starting from the alginate network, coating the primary particles and extending in the secondary particles, but PUA did not fill the space within secondary particles completely.
SEM (Fig. 4) showed that all samples were fibrous. As has been observed before for $\mathrm{X}$-Ca-alginate aerogels prepared using Desmodur N3300, ${ }^{32,33}$ PUA coated the alginate network conformally and the micromorphology remained the same. The fact that the primary particle radii, calculated from $\mathrm{N}_{2}$ sorption and skeletal density data (Table 2), were larger after crosslinking is a strong indication that the polymer growth on the skeletal network followed the contours of the network down to the primary particle level. SEM images of the surface of the beads revealed the presence of a thin skin with a denser fibrous morphology. Although much denser, the skin is still porous allowing gases to go through it into the interior of the beads, i.e., during $\mathrm{N}_{2}$-sorption porosimetry or He-pycnometry. An analogous observation has been made in PUA beads prepared from Desmodur N3300 and ethylenediamine, ${ }^{59}$ and X-Ca-alginate and X-chitosan beads from Desmodur N3300. ${ }^{33}$ In all cases the formation of the skin was attributed to the higher concentration of the gelation agent and/or catalyst on the surface of the droplet containing Desmodur N3300, which caused a fast reaction and the formation of a crust on the surface, while the diffusion of the gelation agent and/or catalyst inside the droplet established a 


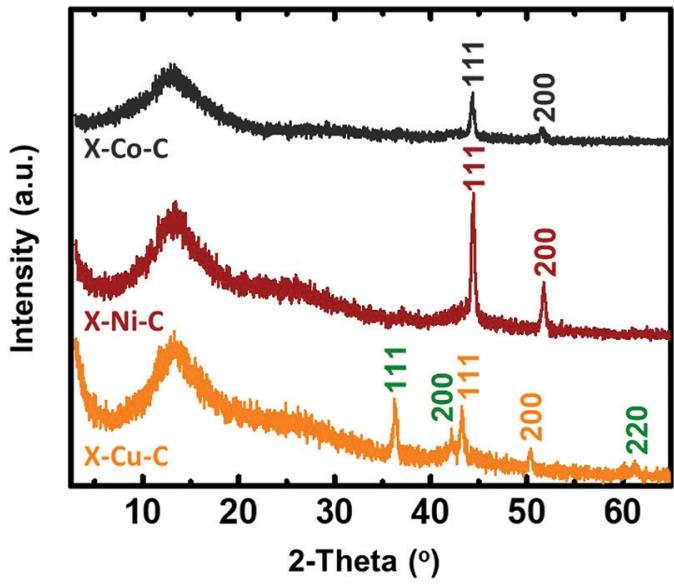

Fig. 5 PXRD patterns of carbon (X-M-C; $\mathrm{M}$ : Co, Ni, Cu) aerogel beads. Planes shown on the spectra correspond to the metals $\mathrm{Co}$ (gray), $\mathrm{Ni}$ (wine red), $\mathrm{Cu}$ (orange) and to the oxide $\mathrm{Cu}_{2} \mathrm{O}$ (green).

concentration gradient, which caused a slower gelation of the interior. The fibrous structure formed for $\mathbf{M}$-alginate hydrogels is retained in the native biopolymer aerogel, ${ }^{60}$ and later on in the X-biopolymer aerogel. ${ }^{32,33}$

\subsection{Pyrolysis of crosslinked $\mathbf{M}$-alginate (X-M-alginate) aerogel beads}

The pyrolysis of $\mathrm{X}-\mathrm{M}$-alginate aerogels ( $\mathrm{M}$ : $\mathrm{Co}, \mathrm{Ni}, \mathrm{Cu}$ ) at $800{ }^{\circ} \mathrm{C}$ resulted in carbon aerogels (X-M-C) with yields in the $33-37 \%$ $\mathrm{w} / \mathrm{w}$ range. $\mathrm{X}-\mathrm{M}-\mathrm{C}$ aerogels retained the spherical shape of their precursor ( $\mathrm{X}-\mathrm{M}$-alginate) aerogels, although they were significantly smaller (diameters: 1.6-1.8 mm; Fig. S6, ESI $\dagger$ ) compared with the $\mathrm{X}-\mathrm{M}$-alginate beads (diameters: 2.7$3.9 \mathrm{~mm}$; Fig. S2, ESI $\dagger$ ). Those carbons were doped with the corresponding metal, as shown by PXRD (Fig. 5 and Fig. S7-S9, ESI $\dagger$ ), as a result of carbothermal reduction of the corresponding metal ions. In the case of the $\mathrm{X}-\mathrm{Cu}$-alginate aerogels, both metallic $\mathrm{Cu}$ and $\mathrm{Cu}_{2} \mathrm{O}$ were detected. The formation of $\mathrm{Cu}_{2} \mathrm{O}$ can be attributed to the well-known redox reaction of $\mathrm{Cu}^{2+}$ and sugars to form $\mathrm{Cu}_{2} \mathrm{O} .{ }^{61}$ Using the Scherrer equation, ${ }^{62}$ the crystallite sizes were calculated at around $22 \mathrm{~nm}$ for all three metals. The broad peak at $13^{\circ}$ was assigned to carbon with some stacking of graphene oxide sheets; the wider $d$-spacing compared with graphite was due to the presence of oxygen functionalities $\left(\mathrm{O}, \mathrm{OH}, \mathrm{H}_{2} \mathrm{O}\right) \cdot{ }^{63,64}$ The metal content of the $\mathrm{X}-\mathrm{M}-\mathrm{C}$ aerogels was calculated from thermogravimetric analysis under $\mathrm{O}_{2}$ (Fig. S10, ESI $\dagger$ ) and from skeletal density data. ${ }^{32,33}$ The results from the two methods are in good agreement (Table 3). $\mathrm{Co}$ in $\mathrm{X}-\mathrm{Co}-\mathrm{C}$ is almost twice as high as $\mathrm{Ni}$ or $\mathrm{Cu}$ in the corresponding carbon aerogels, reflecting the relative amounts of metal in the parent $\mathrm{X}-\mathrm{M}$-alginate aerogels (Table 1).

The Raman spectra of the $\mathrm{X}-\mathrm{M}-\mathrm{C}$ aerogels (Fig. 6 left) exhibited D bands (breathing mode) located around $1355 \mathrm{~cm}^{-1}$ and $\mathrm{G}$ bands (stretching mode) located around $1580 \mathrm{~cm}^{-1}$ (Fig. S11, ESI $\dagger$ ). The corresponding values for the carbon aerogels obtained from Desmodur RE-derived PUA were at $1352 \mathrm{~cm}^{-1}$ (D) and $1597 \mathrm{~cm}^{-1}(\mathrm{G}) .^{10}$ The high overlap of these two bands, and
Table 3 Metal (M) content of carbon (X-M-C; M: Co, Ni, Cu) aerogel beads, calculated via two different methods as indicated

\begin{tabular}{lll}
\hline Sample $^{a}$ & $\begin{array}{l}\mathrm{M}(\%) \text { from TGA } \\
\text { under } \mathrm{O}_{2}{ }^{b}\end{array}$ & $\begin{array}{l}\mathrm{M}(\%) \text { from skeletal } \\
\text { density data }\end{array}$ \\
\hline $\mathrm{X}-\mathrm{Co}-\mathrm{C}$ & 22 & 28 \\
$\mathrm{X}-\mathrm{Ni}-\mathrm{C}$ & 17 & 15 \\
$\mathrm{X}-\mathrm{Cu}-\mathrm{C}$ & 12 & $19^{d}$
\end{tabular}

${ }^{a}$ Carbon aerogel beads $(\mathrm{X}-\mathrm{M}-\mathrm{C})$ derived from the pyrolysis of the corresponding $\mathrm{X}-\mathrm{M}$-alginate $(\mathrm{M}$ : $\mathrm{Co}, \mathrm{Ni}, \mathrm{Cu})$ aerogel beads at $800{ }^{\circ} \mathrm{C}$ under Ar for $5 \mathrm{~h} .{ }^{b}$ Metal (M) content calculated from thermogravimetric analysis data under $\mathrm{O}_{2}$ (Fig. S10, ESI). The residue at $800{ }^{\circ} \mathrm{C}$ was attributed to the corresponding oxides $\left(\mathrm{Co}_{3} \mathrm{O}_{4}, \mathrm{NiO}\right.$ and $\left.\mathrm{CuO}\right)$ and the metal was calculated. ${ }^{c}$ Metal $(\mathrm{M})$ content calculated according to the formula: $\left[\left(\rho_{\mathrm{SM}} / \rho_{\mathrm{S} \mathrm{X}-\mathrm{M}-\mathrm{C}}\right) \times\left(\rho_{\mathrm{s} \text { carbon }}-\rho_{\mathrm{SX}-\mathrm{M}-\mathrm{C}}\right) /\left(\rho_{\mathrm{s} \text { carbon }}-\rho_{\mathrm{SM}}\right)\right] \times 100 .{ }^{32}$ Values for $\rho_{\mathrm{SX}-\mathrm{M}-\mathrm{C}}$ were taken from Table 6 below, and the values for $\rho_{\text {s carbon }}\left(2 \mathrm{~g} \mathrm{~cm}^{-3}\right)$ and $\rho_{\mathrm{sM}}\left(8.900 \mathrm{~g} \mathrm{~cm}^{-3}\right.$ for $\mathrm{Co}, 8.908 \mathrm{~g} \mathrm{~cm}^{-3}$ for $\mathrm{Ni}$, $8.96 \mathrm{~g} \mathrm{~cm}^{-3}$ for $\mathrm{Cu}$ and $6 \mathrm{~g} \mathrm{~cm}^{-3}$ for $\mathrm{Cu}_{2} \mathrm{O}$ ) were taken from the literature. ${ }^{d}$ Both $\mathrm{Cu}$ and $\mathrm{Cu}_{2} \mathrm{O}$ are formed during the pyrolysis of $\mathrm{X}-$ $\mathrm{Cu}-\mathrm{alg}$ (as shown by the PXRD data; Fig. 5).

especially the width of the $\mathrm{D}$ band, indicate a high degree of disorder, apparent also from the $I(\mathrm{D}) / I(\mathrm{G})$ ratio (Fig. S11, ESI $\dagger$ ), which is higher than 1.1 in all cases, indicating also a low degree of graphitization and a large number of defects. ${ }^{27}$ Among the three metals studied (Co, Ni, Cu), Co showed the highest degree of graphitization. In addition, the broad low-intensity bump observed in the second-order band regime (around $2800 \mathrm{~cm}^{-1}$ ) suggests the presence of a higher-ordered structure. ${ }^{27}$ The crystallite size $\left(L_{\mathrm{a}}\right)$ of the graphitic domains of $\mathrm{X}-\mathrm{M}-\mathrm{C}$ was calculated using eqn (1), ${ }^{65}$ and it was found to be $14-15 \mathrm{~nm}$ for all three aerogels.

$$
L_{\mathrm{a}}(\mathrm{nm})=2.4 \times 10^{-10} \cdot \lambda_{\text {exc. }}{ }^{4} \cdot\left[\frac{I(D)}{I(G)}\right]^{-1}
$$

XPS surface analysis detected $\mathrm{C}, \mathrm{O}, \mathrm{N}$ and the respective metals ( $\mathrm{M}$ : $\mathrm{Co}, \mathrm{Ni}, \mathrm{Cu}$ ) in all $\mathrm{X}-\mathrm{M}-\mathrm{C}$ aerogels (Fig. 7 and Fig. S12, in agreement with the EDX data shown in Fig. S13, ESI $\dagger$ ). $\mathrm{Mg}$ (unknown contaminant) was also detected in one case $(<1 \%)$. Table 4 shows the atomic concentration (\%) of the above elements, as derived from C1s, O1s, N1s, M2p, Mg2p. The $\mathrm{C} / \mathrm{O}$ and $\mathrm{C} / \mathrm{N}$ ratios were not very different for the three samples; the $\mathrm{C} / \mathrm{O}$ ratio increased slightly in the order $\mathrm{X}-\mathrm{Cu}-\mathrm{C}$ $>\mathrm{X}-\mathrm{Ni}-\mathrm{C}>\mathrm{X}-\mathrm{Co}-\mathrm{C}$. The $\mathrm{C} / \mathrm{M}$ ratio increased in the reverse order. Table 5 summarizes the percent atomic allocation of carbon, oxygen and nitrogen to the various groups. The C1s peaks (Fig. 7D-F) are comprised of five components, namely the $\mathrm{sp}^{2}$ and $\mathrm{sp}^{3}$ components located at 284.5-284.6 eV and 285.4-285.5 eV, respectively, the $\mathrm{C}-(\mathrm{O}, \mathrm{N})$ component at 286.8$286.9 \mathrm{eV}$, the $\mathrm{C}=\mathrm{O}$ carbonyl component at $287.8-288.3 \mathrm{eV}^{66,67}$ and also the $\pi-\pi^{*}$ satellite at $290.6-290.8 \mathrm{eV} .^{68}$ The deconvoluted O1s peaks (Fig. 7G-I) show the presence of the following groups in all three carbon aerogels: (a) metal(II) oxide $\left(\mathrm{M}^{\mathrm{II}} \mathrm{O}\right)$ at $529.8-530.2 \mathrm{eV}^{69}$ (b) $\mathrm{O}^{-70,71}$ or $\mathrm{O}$ atoms at defect sites ${ }^{23}$ or $\mathrm{HO}^{-}$ or $\mathrm{M}(\mathrm{OH})_{2}{ }^{69}$ at $531.0-531.6 \mathrm{eV}$, (c) carbonyl oxygen $(\mathrm{C}=\mathrm{O})$ at $532.2-532.6 \mathrm{eV},{ }^{72,73}$ and $(\mathrm{d})$ epoxide $(\mathrm{C}-\mathrm{O}-\mathrm{C})^{72,73}$ or pyrylium $\left(\mathrm{C}-\mathrm{O}^{+}=\mathrm{C}\right)^{74}$ oxygen at 533.3-533.8 eV. Based on control experiments with authentic samples, the peak at 533.1-534.3 eV in 

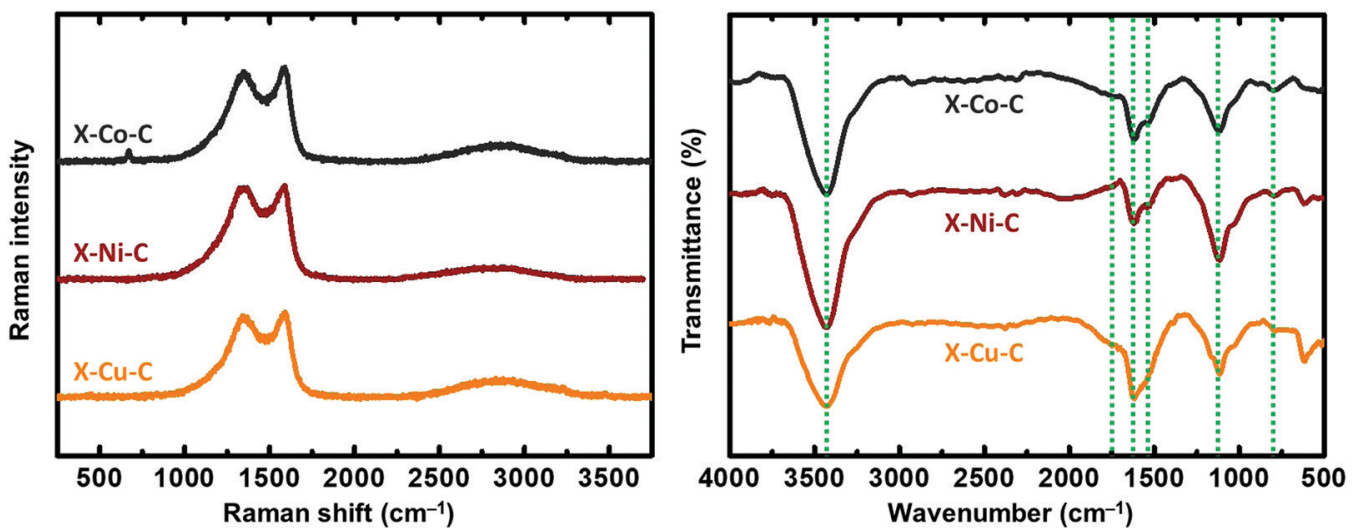

Fig. 6 Representative Raman spectra (left) and ATR-FTIR spectra (right) of carbon (X-M-C; M: Co, Ni, Cu) aerogel beads, as indicated. Dashed lines show the position of the characteristic peaks discussed in the text.

the carbon aerogels derived from phenolic polymers has been assigned to heteroaromatic pyrylium oxygen and the peak at 530.9-531.6 eV to $\mathrm{O}^{-8,75}$ thus accounting for charge compensation. In addition to the above, Fig. 7I shows one more contribution at $530.5 \mathrm{eV}$ for the oxygen of $\mathrm{Cu}_{2} \mathrm{O},{ }^{69}$ which has also been detected with PXRD (Fig. 5). The deconvoluted N1s photoemission peaks (Fig. 7J-L) show the presence of only two nitrogen groups: pyridinic nitrogen at $398.2-398.5 \mathrm{eV}$ and graphitic nitrogen at $400.8-400.9 \mathrm{eV} \cdot{ }^{76}$ Graphitic and pyridinic $\mathrm{N}$ are considered as active sites for the oxygen reduction reaction (ORR), while other $\mathrm{N}$ species (e.g., pyrrolic $\mathrm{N}$ ) have a disputable role in the ORR. ${ }^{21}$ Therefore, it is considered positive that $\mathrm{X}-\mathrm{M}-\mathrm{C}$ aerogels show only graphitic and pyridinic $\mathrm{N}$, as opposed to most alginate-derived carbons from the literature. The deconvoluted $2 \mathrm{p}_{3 / 2}$ photoemission peaks of Co, $\mathrm{Ni}$ and $\mathrm{Cu}$ are shown in Fig. S12 (ESI $\dagger$ ). They all show that the metal can be found in the 2+ oxidation state, as the corresponding oxides or hydroxides. ${ }^{69}$ Cobalt was found as $\mathrm{CoO}$ (peak at $780.6 \mathrm{eV}$ and satellite peak at $786.9 \mathrm{eV})$ or $\mathrm{Co}(\mathrm{OH})_{2}(783.3 \mathrm{eV})$. Nickel was also found as $\mathrm{NiO}(854.2 \mathrm{eV})$ or $\mathrm{Ni}(\mathrm{OH})_{2}(855.9 \mathrm{eV})$. The latter peak could also be attributed to a component of NiO, which is due to multiplet splitting. The strong satellite of Ni2 $\mathrm{p}_{3}$ / ${ }_{2}$ located at $861.8 \mathrm{eV}$ is due to contributions arising from both $\mathrm{NiO}$ and $\mathrm{Ni}(\mathrm{OH})_{2}$. Copper was found in both the +1 and the +2 oxidation states. The peaks at $932.4 \mathrm{eV}$ and $933.4 \mathrm{eV}$ were attributed to $\mathrm{Cu}_{2} \mathrm{O}$ and $\mathrm{CuO}$, respectively, and the peak at $934.7 \mathrm{eV}$ to $\mathrm{Cu}(\mathrm{OH})_{2}$. The two satellites located at $941.3 \mathrm{eV}$ and $944.2 \mathrm{eV}$ are typical of $\mathrm{Cu}^{2+}$. It should be noted that no crystalline phase wherein the metal was in its +2 oxidation state was observed by PXRD in any of the $\mathrm{X}-\mathrm{M}-\mathrm{C}$ aerogels (refer to Fig. 5). The formation of those species could be attributed to post-pyrolysis reactions of the metals on the surface of the material with air, ${ }^{21}$ thus also explaining the absence of XPS peaks due to metallic $\mathrm{Co}$, $\mathrm{Ni}$ or $\mathrm{Cu}$.

In agreement with XPS data, the FTIR spectra of the X-M-C aerogels (Fig. 6 right) showed peaks around $3430 \mathrm{~cm}^{-1}(\mathrm{O}-\mathrm{H}$ stretching), $1725 \mathrm{~cm}^{-1}$ ( $\mathrm{C}=\mathrm{O}$ stretching), $1627 \mathrm{~cm}^{-1}(\mathrm{C}=\mathrm{C}$ or $\mathrm{C}=\mathrm{N}$ or adsorbed water), $1540 \mathrm{~cm}^{-1}(\mathrm{C}-\mathrm{C}(\mathrm{O})$ stretching of pyrylium), ${ }^{74,77} 1115 \mathrm{~cm}^{-1}$ (C-O stretching) and $798 \mathrm{~cm}^{-1}$
(C-N heterocycle stretching). ${ }^{78}$ The low intensity of the $\mathrm{C}=\mathrm{O}$ stretching peak indicates only a minor contribution from carbonyl groups.

Selected material properties of the $\mathrm{X}-\mathrm{M}-\mathrm{C}$ aerogels (M: Co, $\mathrm{Ni}, \mathrm{Cu}$ ) are summarized in Table 6 . The same properties of $\mathrm{X}-\mathrm{Ca}-\mathrm{C}$ are included in Table 6 for comparison; however, this carbon material did not show any BET surface area, and it was not pursued further. That was attributed to the $\mathrm{Ca}^{2+}$ ions, which cannot be reduced carbothermally, and was considered as a first indication that the metal has a profound effect on the formation of the carbon material, which is further discussed below. Bulk densities were higher than those of the corresponding $\mathrm{X}-\mathrm{M}$-aerogels, despite the mass loss, reflecting the large shrinkage of those materials during pyrolysis. Skeletal densities are all higher than $2 \mathrm{~g} \mathrm{~cm}^{-3}$. The values of bulk and skeletal densities were not very much different for the three different aerogels; therefore, the porosities were also very similar $(92 \% \mathrm{v} / \mathrm{v}$ for $\mathrm{X}-\mathrm{Co}-\mathrm{C}$ and $\mathrm{X}-\mathrm{Cu}-\mathrm{C}$ and $88 \% \mathrm{v} / \mathrm{v}$ for $\mathrm{X}-\mathrm{Ni}-\mathrm{C})$.

The evaluation of open porosity (accessible from outside) was conducted by comparing $V_{\text {Total }}$ (the total pore volume) with $V_{1.7-300 \mathrm{~nm}}$ (the total volume of $\mathrm{N}_{2}$ adsorbed during $\mathrm{N}_{2}$-sorption porosimetry as $P / P_{\mathrm{o}} \rightarrow 1.0$; Table 6 ). The $V_{\text {Total }}$ values are significantly higher than $V_{1.7-300 \mathrm{~nm}}$, showing that the materials are mostly macroporous, in agreement with the shape of $\mathrm{N}_{2}$-sorption plots (Fig. S14, ESI $\dagger$ ). As observed for both native $\mathrm{M}$-alginate and X-M-alginate aerogels, the plot of $1 / \rho_{\mathrm{b}} v s . V_{\text {Total }}$ was linear (Fig. S5, ESI $\dagger$ ), indicating that the $\mathrm{X}-\mathrm{M}-\mathrm{C}$ aerogels had no closed porosity. Pore size distributions by the $\mathrm{BJH}$ method (Fig. S14, ESI $\dagger$ ), for pores in the range of $1.7-300 \mathrm{~nm}$, showed maxima around $45 \mathrm{~nm}$ for $\mathrm{X}-\mathrm{Co}-\mathrm{C}$ and $\mathrm{X}-\mathrm{Ni}-\mathrm{C}$ and at $34 \mathrm{~nm}$ for $\mathrm{X}-\mathrm{Cu}-\mathrm{C}$.

The BET surface areas of the $\mathrm{X}-\mathrm{M}-\mathrm{C}$ aerogels were significantly higher than those of their parent aerogels (by a factor of 1.7). More importantly, the micropore surface areas were increased significantly and are now in the range of 49 to $65 \%$ of the total BET surface area. Microporosity was probed with $\mathrm{CO}_{2}$ adsorption porosimetry up to 1 bar at $0{ }^{\circ} \mathrm{C}$ (Fig. 8). The amount of $\mathrm{CO}_{2}$ adsorbed was similar for $\mathrm{X}-\mathrm{Cu}-\mathrm{C}\left(3.5 \mathrm{mmol} \mathrm{g}^{-1}\right)$ and $\mathrm{X}-\mathrm{Ni}-\mathrm{C}$ 
$\mathrm{X}-\mathrm{Co}-\mathrm{C}$
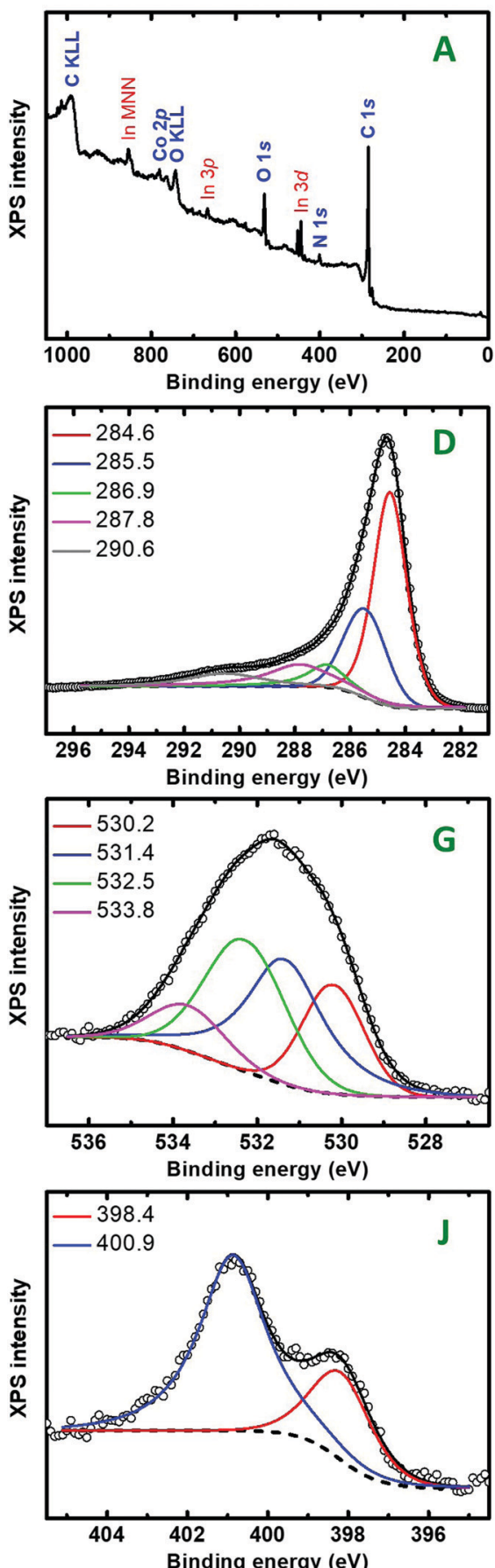

$\mathrm{X}-\mathrm{Ni}-\mathrm{C}$
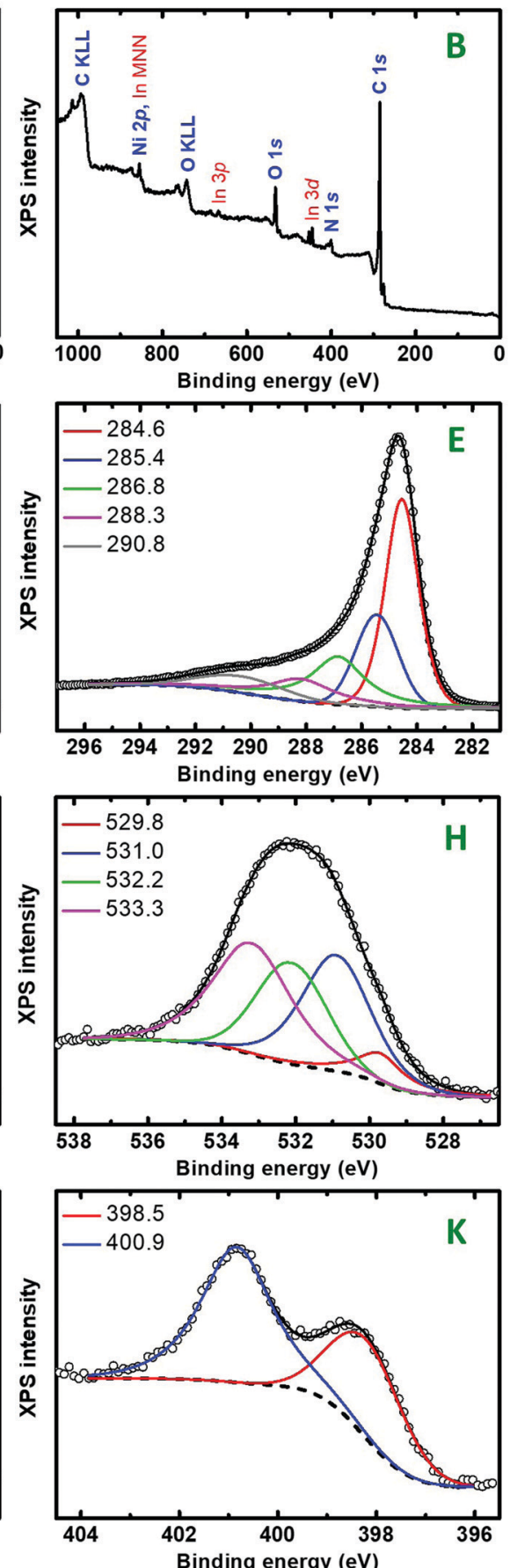

$\mathrm{X}-\mathrm{Cu}-\mathrm{C}$
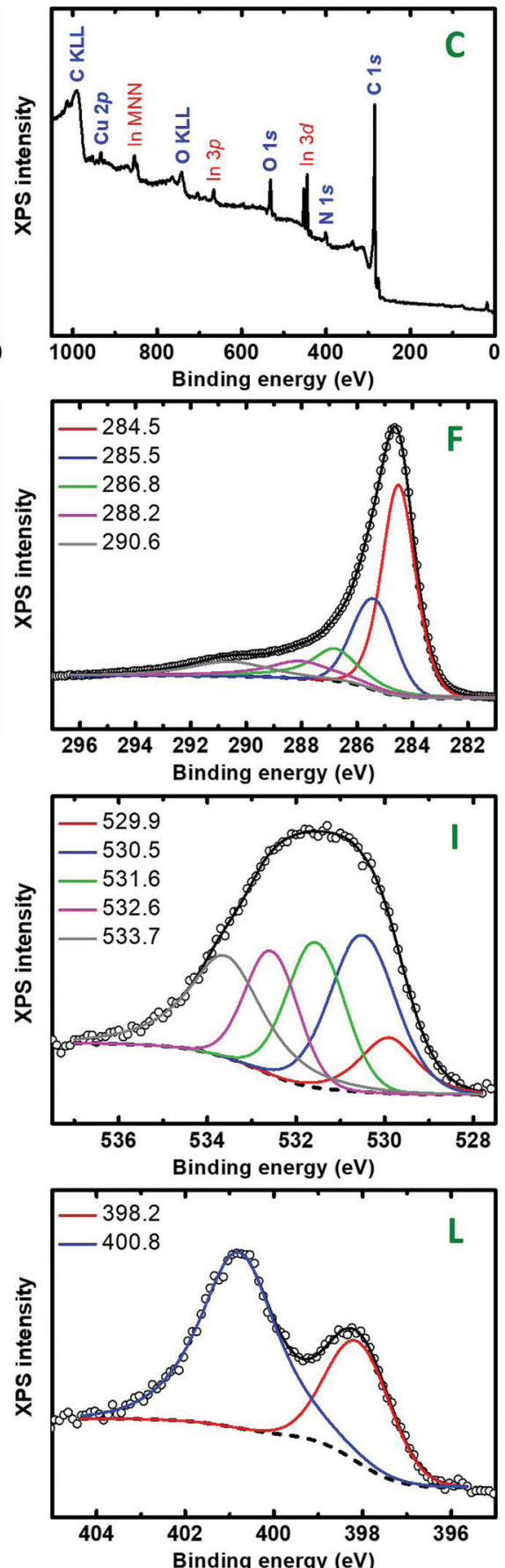

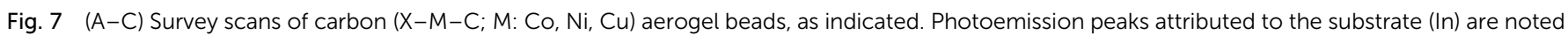

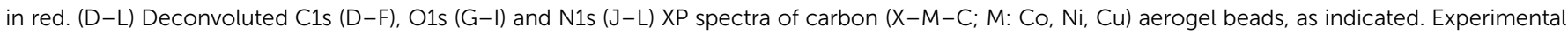

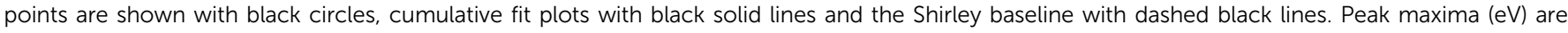
provided within the frames.

(3.1 $\left.\mathrm{mmol} \mathrm{g}^{-1}\right)$, and lower for $\mathrm{X}-\mathrm{Co}-\mathrm{C}\left(2.5 \mathrm{mmol} \mathrm{g}^{-1}\right)$. Pore size distributions (for pores smaller than $<1 \mathrm{~nm}$ ) were calculated from the $\mathrm{CO}_{2}$-adsorption isotherms using the DFT method (Fig. 8) ${ }^{79}$ The three DFT plots were almost identical, with micropores distributed in the range of 0.4-1.0 nm. To check whether or not the materials include micropores larger than $1 \mathrm{~nm}$
Table 4 Surface atomic composition (\%) of carbon (X-M-C; M: Co, Ni, $\mathrm{Cu}$ ) aerogel beads, as extracted from XPS analysis

\begin{tabular}{lllllllll}
\hline Sample & $\mathrm{C}$ & $\mathrm{O}$ & $\mathrm{N}$ & $\mathrm{M}$ & $\mathrm{Mg}$ & $\mathrm{C} / \mathrm{O}$ & $\mathrm{C} / \mathrm{N}$ & $\mathrm{C} / \mathrm{M}$ \\
\hline $\mathrm{X}-\mathrm{Co}-\mathrm{C}$ & 86.68 & 8.51 & 3.20 & 1.61 & - & 10.19 & 27.09 & 53.84 \\
$\mathrm{X}-\mathrm{Ni}-\mathrm{C}$ & 87.30 & 6.70 & 2.92 & 2.19 & 0.89 & 13.03 & 29.90 & 39.86 \\
X-Cu-C & 87.21 & 5.61 & 3.72 & 3.46 & - & 15.55 & 23.44 & 25.21
\end{tabular}


Table 5 Distribution (\%) of carbon, oxygen and nitrogen groups in carbon (X-M-C; $\mathrm{M}$ : $\mathrm{Co}, \mathrm{Ni}, \mathrm{Cu}$ ) aerogel beads, as obtained from XPS analysis

\begin{tabular}{|c|c|c|c|c|}
\hline & Peak max. $(\mathrm{eV})$ & $\mathrm{X}-\mathrm{Co}-\mathrm{C}$ & $\mathrm{X}-\mathrm{Ni}-\mathrm{C}$ & $\mathrm{X}-\mathrm{Cu}-\mathrm{C}$ \\
\hline \multicolumn{5}{|l|}{ C1s } \\
\hline $\mathrm{sp}^{2} \mathrm{C}$ & $284.5-284.6$ & 47.70 & 39.84 & 45.00 \\
\hline $\mathrm{sp}^{3} \mathrm{C}$ & $285.4-285.5$ & 24.06 & 21.18 & 23.18 \\
\hline $\mathrm{sp}^{2} / \mathrm{sp}^{3}$ & & 1.98 & 1.88 & 1.94 \\
\hline $\mathrm{C}-(\mathrm{O}, \mathrm{N})$ & $286.8-286.9$ & 8.31 & 20.07 & 13.71 \\
\hline $\mathrm{C}=\mathrm{O}$ & $287.8-288.3$ & 13.04 & 11.29 & 10.07 \\
\hline$\pi \rightarrow \pi^{*}$ & $290.6-290.8$ & 7.97 & 7.62 & 8.03 \\
\hline \multicolumn{5}{|l|}{ O1s } \\
\hline $\mathrm{M}^{\mathrm{II}} \mathrm{O}$ & $529.8-530.2$ & 21.11 & 7.62 & 8.99 \\
\hline $\mathrm{Cu}_{2} \mathrm{O}$ & 530.5 & & & 27.83 \\
\hline $\mathrm{O}^{-}$or $\mathrm{O}$ or $\mathrm{HO}^{-}$ & $531.0-531.6$ & 35.08 & 31.21 & 22.22 \\
\hline $\mathrm{C}=\mathrm{O}$ & $532.2-532.6$ & 33.22 & 26.21 & 17.31 \\
\hline $\mathrm{C}-\mathrm{O}-\mathrm{C}$ or $\mathrm{C}-\mathrm{O}^{+}=\mathrm{C}$ & $533.3-533.8$ & 10.59 & 34.96 & 23.65 \\
\hline \multicolumn{5}{|l|}{ N1s } \\
\hline Pyridinic N & $398.2-398.5$ & 27.97 & 39.39 & 34.00 \\
\hline Graphitic N & $400.8-400.9$ & 72.03 & 60.61 & 66.00 \\
\hline Graphitic/pyridinic & & 2.58 & 1.54 & 1.94 \\
\hline
\end{tabular}

(that cannot be accounted for by the DFT method), the DubininRadushkevich (DR) method was employed, which has been developed based on volume-filling of microporous carbons, by recognizing the fact that micropores are of the same order of magnitude as the adsorbate itself. ${ }^{79}$ DR plots are shown in Fig. S15
$(\mathrm{ESI} \dagger)$. The specific pore volumes calculated from the DR method were higher than those from the DFT method (Table 7), indicating the presence of small pores larger than $1 \mathrm{~nm}$. Average pore diameters derived from the DR method (Table 7) indicate that most of those pores could not be classified as large micropores (e.g., in the range of 1-2 $\mathrm{nm}$ ), but rather as small mesopores.

Experimental $\mathrm{CO}_{2}$ uptake is presented in Table 7, and is compared with the theoretical uptake values calculated for: (a) monolayer coverage of the entire BET surface area with $\mathrm{CO}_{2}$ $\left(0.17 \mathrm{~nm}^{2} \text { per molecule }\right)^{79}$ and (b) monolayer coverage of the micropore surface area only. By comparison, it is obvious that the experimental uptake correlates very well with the monolayer coverage of the micropore surface area, showing that $\mathrm{CO}_{2}$ is adsorbed only in the micropores. The $\mathrm{CO}_{2}$ uptake of all three carbon aerogels is very similar $\left(2.5-3.5 \mathrm{mmol} \mathrm{g}^{-1}\right)$ and is comparable to that of carbon aerogels obtained from the pyrolysis of polyamide $\left(3.07 \mathrm{mmol} \mathrm{g}^{-1}\right)^{13}$ or poly(urethane acrylate $)\left(2.50 \mathrm{mmol} \mathrm{g}^{-1}\right)^{46}$ aerogels prepared using Desmodur RE.

SEM images of X-M-C aerogels (Fig. 9) showed that the three different aerogels did not have the same morphology, unlike native $\mathbf{M}$-alginate and $\mathbf{X}-\mathbf{M}$-alginate aerogels that all had the same morphology (Fig. 4), as discussed above. The

Table 6 Selected material properties of carbon (X-M-C; M: Co, Ni, Cu) aerogel beads, and of X-Ca-C

\begin{tabular}{|c|c|c|c|c|c|c|c|c|}
\hline Sample $^{a}$ & $\begin{array}{l}\text { Yield of } \\
\text { pyrolysis } \\
(\%)\end{array}$ & $\begin{array}{l}\text { Bulk } \\
\text { density } \\
\rho_{\mathrm{b}}\left(\mathrm{g} \mathrm{cm}^{-3}\right)\end{array}$ & $\begin{array}{l}\text { Skeletal } \\
\text { density } \\
\rho_{\mathrm{s}}\left(\mathrm{g} \mathrm{cm}^{-3}\right)\end{array}$ & $\begin{array}{l}\text { Porosity }^{b} \\
\Pi(\% \mathrm{v} / \mathrm{v})\end{array}$ & $\begin{array}{l}\text { BET surf. } \\
\text { area } \\
\sigma\left(\mathrm{m}^{2} \mathrm{~g}^{-1}\right) \\
{[\text { micropore }} \\
\text { surf. area }]^{c}\end{array}$ & $\begin{array}{l}V_{\text {Total }}{ }^{d} \\
\left(V_{1.7-300 \mathrm{~nm}}\right)^{e} \\
\left(\mathrm{~cm}^{3} \mathrm{~g}^{-1}\right)\end{array}$ & $\begin{array}{l}\text { Av. pore } \\
\text { diam } f \\
\left(4 V_{\text {Total }} / \sigma\right) \\
(\mathrm{nm})\end{array}$ & $\begin{array}{l}\text { Particle } \\
\text { radius }^{g} \\
(\mathrm{~nm})\end{array}$ \\
\hline $\mathrm{X}-\mathrm{Ca}-\mathrm{C}$ & 23 & $0.76 \pm 0.06$ & $1.119 \pm 0.002$ & 32 & $<10$ & - & - & - \\
\hline $\mathrm{X}-\mathrm{Co}-\mathrm{C}$ & 33 & $0.23 \pm 0.02$ & $2.58 \pm 0.04$ & 91 & $426[208]$ & $3.8(0.6)$ & $12(38)$ & $2.7(5.3)$ \\
\hline $\mathrm{X}-\mathrm{Ni}-\mathrm{C}$ & 34 & $0.32 \pm 0.07$ & $2.26 \pm 0.01$ & 86 & $460[301]$ & $2.7(0.8)$ & $8.0(23)$ & $2.9(8.3)$ \\
\hline $\mathrm{X}-\mathrm{Cu}-\mathrm{C}$ & 37 & $0.25 \pm 0.02$ & $2.35 \pm 0.02$ & 89 & $541[319]$ & $3.6(1.1)$ & $9.0(26)$ & $2.4(5.8)$ \\
\hline
\end{tabular}

${ }^{a}$ Carbon $(\mathrm{X}-\mathrm{M}-\mathrm{C})$ aerogel beads derived from the pyrolysis of the corresponding $\mathrm{X}-\mathrm{M}$-alginate $(\mathrm{M}$ : $\mathrm{Ca}, \mathrm{Co}, \mathrm{Ni}, \mathrm{Cu})$ aerogel beads at $800{ }^{\circ} \mathrm{C}$ under $\mathrm{Ar}$ for $5 \mathrm{~h} .{ }^{b}$ Porosity calculated according to the formula: $\left(\rho_{\mathrm{s}}-\rho_{\mathrm{b}}\right) / \rho_{\mathrm{s}}$, where $\rho_{\mathrm{s}}$ : skeletal density and $\rho_{\mathrm{b}}$ : bulk density. ${ }^{c}$ Micropore surface area via $t$ plot analysis, according to the Harkins and Jura model. ${ }^{d}$ Total pore volume calculated according to the formula: $1 / \rho_{\mathrm{b}}-1 / \rho_{\mathrm{s}}{ }^{e}{ }^{e}$ Cumulative volume of pores between 1.7 and $300 \mathrm{~nm}$ from $\mathrm{N}_{2}$-sorption data and the BJH desorption method. ${ }^{f}$ Calculated using the $4 V / \sigma$ method; $V$ was set equal to the maximum volume of $\mathrm{N}_{2}$ adsorbed along the isotherm as $P / P_{\mathrm{o}} \rightarrow 1.0$. For the number in parentheses, $V$ was set equal to $V_{\text {Total }}$ from the previous column. ${ }^{g}$ Particle radius calculated using the formula: $r=3 /\left(\rho_{\mathrm{s}} \times \sigma\right)$, where $\sigma$ : BET surface area. For the number in parentheses, $\sigma$ was set equal to the external surface area, $\sigma_{\text {ext }}$, calculated from the BET surface area minus the micropore surface area.
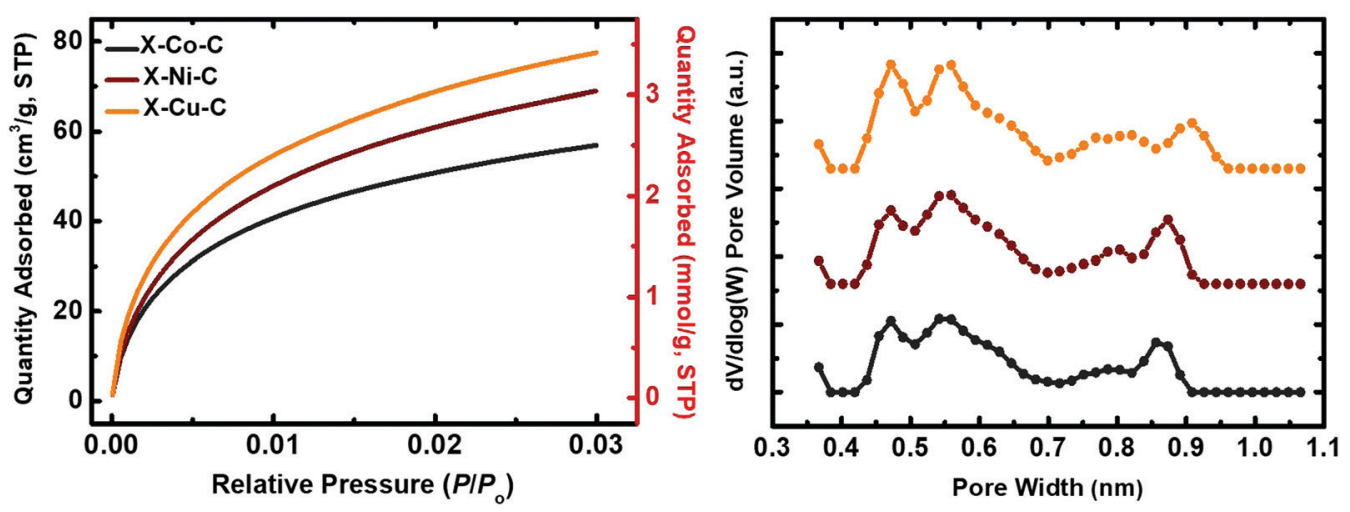

Fig. 8 Left: $\mathrm{CO}_{2}$-sorption diagrams of carbon (X-M-C; $\mathrm{M}$ : $\mathrm{Co}, \mathrm{Ni}, \mathrm{Cu}$ ) aerogel beads, as indicated. Right: Pore size distribution calculated from $\mathrm{CO} 2$ adsorption data using the DFT method. 
Table 7 Micropore analysis and $\mathrm{CO}_{2}$ uptake of carbon (X-M-C; $\mathrm{M}$ : $\mathrm{Ca}, \mathrm{Co}, \mathrm{Ni}, \mathrm{Cu}$ ) aerogel beads

\begin{tabular}{|c|c|c|c|c|c|c|}
\hline \multirow[b]{2}{*}{ Sample ${ }^{a}$} & \multicolumn{2}{|c|}{ Specific micropore volume $\left(\mathrm{cm}^{3} \mathrm{~g}^{-1}\right)$} & \multirow{2}{*}{$\frac{\text { Av. pore diam. }{ }^{b}(\mathrm{~nm})}{\text { DR method }}$} & \multicolumn{3}{|c|}{$\mathrm{CO}_{2}$ uptake $\left(\mathrm{mmol} \mathrm{g}^{-1}\right)$} \\
\hline & DFT method & DR method & & Measured & From BET surf. area ${ }^{c}$ & From micropore surf. area ${ }^{d}$ \\
\hline $\mathrm{X}-\mathrm{Co}-\mathrm{C}$ & 0.10 & 0.17 & 3.3 & 2.5 & 4.2 & 2.0 \\
\hline $\mathrm{X}-\mathrm{Cu}-\mathrm{C}$ & 0.13 & 0.24 & 3.0 & 3.5 & 5.3 & 3.1 \\
\hline
\end{tabular}

3.0

5.3

3.1

${ }^{a}$ Carbon (X-M-C) aerogel beads derived from the pyrolysis of the corresponding $\mathrm{X}-\mathrm{M}$-alginate (M: Co, Ni, $\mathrm{Cu}$ ) aerogel beads at $800{ }^{\circ} \mathrm{C}$ under $\mathrm{Ar}$ for 5 h. ${ }^{b}$ Calculated using the $4 V / \sigma^{\prime}$ method; $V$ was set equal to the micropore volume calculated from the Dubinin-Radushkevich (DR) method and $\sigma^{\prime}$ was set equal to the micropore surface area (Table 3). ${ }^{c}$ Calculated by dividing the BET surface area over the area occupied by each $\mathrm{CO}_{2}$ molecule $\left(0.17 \mathrm{~nm}^{2}\right)$, over the Avogadro number. ${ }^{d}$ Calculated by dividing the micropore surface area over the area occupied by each $\mathrm{CO}_{2}$ molecule $\left(0.17 \mathrm{~nm}^{2}\right)$, over the Avogadro number.
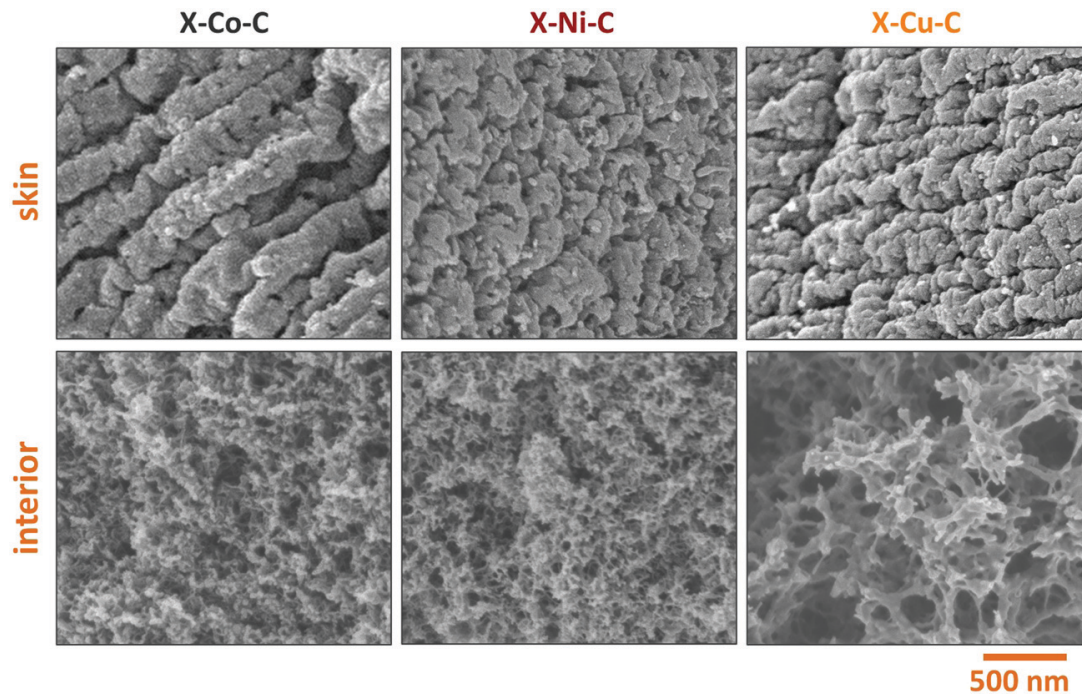

Fig. 9 Representative SEM images of carbon (X-M-C; M: Co, Ni, Cu) aerogel beads, as indicated.

metals affect the nanostructure of the corresponding carbons. The morphologies of $\mathrm{X}-\mathrm{Co}-\mathrm{C}$ and $\mathrm{X}-\mathrm{Ni}-\mathrm{C}$ are very similar, while the morphology of $\mathrm{X}-\mathrm{Cu}-\mathrm{C}$ is quite different. This property is interesting and will be further investigated. The morphology of $\mathrm{X}-\mathrm{Ca}-\mathrm{C}$ is completely different (Fig. S16, ESI $\dagger$ left). It is featureless and one can also see large chunks of calcium species $\left(\mathrm{CaO}\right.$ or $\left.\mathrm{Ca}(\mathrm{OH})_{2}\right)$. After treatment with an aqueous $\mathrm{HCl}$ solution and removal of the calcium species, the morphology of the remaining carbon resembles the morphology of the $\mathrm{X}-\mathrm{Cu}-\mathrm{C}$ aerogel, although the fibers were thicker (Fig. S16, ESI $\dagger$ right). This also supports the finding that the metal ion clearly affects the carbonization process and the resulting materials.

\section{Conclusions}

We have prepared polyurea-crosslinked alginate aerogels $(\mathrm{X}-\mathrm{M}$-alginate; $\mathrm{M}: \mathrm{Ca}, \mathrm{Co}, \mathrm{Ni}, \mathrm{Cu})$ and the corresponding carbon aerogels $(\mathrm{X}-\mathrm{M}-\mathrm{C}$; $\mathrm{M}$ : $\mathrm{Co}, \mathrm{Ni}, \mathrm{Cu})$. The $\mathrm{X}-\mathrm{M}$-alginate aerogels were prepared via reaction of an aromatic triisocyanate (Desmodur RE) with both the -OH groups on the surface of pre-formed $\mathrm{M}$-alginate wet gels, forming urethane groups, and with water adsorbed on the inner surface of the wet gels, leading to the formation and accumulation of a nanometerthick conformal polyurea (PUA) coating over the skeletal framework of the biopolymer aerogel. The $\mathrm{X}-\mathrm{M}$-alginate aerogels consisted of $49-63 \%$ PUA and their metal content was in the range of $2-7 \%$. Microscopically, all the X-M-alginate aerogels were fibrous, just like the corresponding native $\mathrm{M}$-alginate aerogels, and were practically identical to each other with porosities up to $94 \% \mathrm{v} / \mathrm{v}$, including macropores, mesopores and micropores, and BET surface areas in the range of 245$486 \mathrm{~m}^{2} \mathrm{~g}^{-1}$, which is roughly the same with that of the native alginate aerogels $\left(258-542 \mathrm{~m}^{2} \mathrm{~g}^{-1}\right)$. Pyrolysis of the $\mathrm{X}-\mathrm{M}-$ alginate aerogels $(\mathrm{M}: \mathrm{Co}, \mathrm{Ni}, \mathrm{Cu})$ at $800{ }^{\circ} \mathrm{C}$ yielded carbon aerogels (X-M-C; $33-37 \% \mathrm{w} / \mathrm{w}$ yield). These $\mathrm{X}-\mathrm{M}-\mathrm{C}$ aerogels retained the spherical shape of their parent $\mathrm{X}-\mathrm{M}$-alginate aerogel beads, although they were significantly smaller (diameters: 1.6-1.8 mm) compared with the $\mathrm{X}-\mathrm{M}$-alginate beads (diameters: 2.7-3.9 mm). Those carbon aerogels were doped with the corresponding metal, as a result of carbothermal reduction of the corresponding metal ions. In the case of $\mathrm{X}-\mathrm{Cu}$-alginate aerogels, both metallic $\mathrm{Cu}$ and $\mathrm{Cu}_{2} \mathrm{O}$ were detected. The crystallite sizes were calculated from XRD data at around $22 \mathrm{~nm}$ for all three metals. X-M-C aerogels were porous $(88-92 \% \mathrm{v} / \mathrm{v})$, containing macropores, mesopores and micropores, with BET 
surface areas in the range of 426-541 $\mathrm{m}^{2} \mathrm{~g}^{-1}$, and micropore surface areas in the range of $208-319 \mathrm{~m}^{2} \mathrm{~g}^{-1}$. The SEM data showed that the three carbon aerogels were fibrous, yet did not have the same morphology (the morphologies of $\mathrm{X}-\mathrm{Co}-\mathrm{C}$ and $\mathrm{X}-\mathrm{Ni}-\mathrm{C}$ were very similar, whereas the morphology of $\mathrm{X}-\mathrm{Cu}-\mathrm{C}$ was different), showing a structure-directing effect of the metal on the nanostructure of the corresponding carbons. PXRD, XPS, Raman and FTIR data showed the presence of oxygen and nitrogen functionalities, in addition to metals. The $\mathrm{X}-\mathrm{M}-\mathrm{C}$ aerogels consisted of carbon with some stacking of graphene oxide sheets (14-15 $\mathrm{nm}$ ), and also a low degree of graphitization and a large number of defects. This work provides a direct method for the preparation of fibrous metal-, oxygen- and nitrogen-doped carbon aerogels in the form of beads, or any other desirable macroscopic shape, from inexpensive biopolymer aerogels. These carbon aerogels have the potential for catalytic and electrochemical applications that will be explored in the future along with optimization of the material properties relevant to the specific application.

\section{Author contributions}

Conceptualization, methodology, project administration and writing (PP), investigation, validation, review and editing (GR, MP, DC, EE, TČ, NS, GM, TI, PG, IS, PP), funding acquisition and resources (GM, TI, PG, IS, PP).

\section{Conflicts of interest}

There are no conflicts to declare.

\section{Acknowledgements}

Work carried out in the frame of the COST-Action "Advanced Engineering and Research of aeroGels for Environment and Life Sciences" (AERoGELS, ref. CA18125) funded by the European Commission. This project has received funding from the European Union's Horizon 2020 research and innovation programme under Grant Agreement No. 685648. This publication reflects the views only of the authors, and the Commission cannot be held responsible for any use, which may be made of the information contained therein. We also thank the General Secretariat for Research and Technology, Greece, and the Special Account of Research Grants of the National and Kapodistrian University of Athens for partial support. PP and MP acknowledge the CERIC-ERIC (proposal number 20187018) for access to experimental facilities and financial support. NS and TI acknowledge support by the project "Materials and Processes for Energy and Environment Applications" (MIS 5002556), which was implemented under the "Action for the Strategic Development on the Research and Technological Sector", funded by the Operational Program "Competitiveness, Entrepreneurship and Innovation" (NSRF 2014-2020) and co-financed by Greece and the European Union (European Regional Development Fund). We thank Dr Vassilis Vamvakas and Ms Maria-Christina Skoulikidou (Nanotechnology and Microsystems Laboratory (NML), Institute of Nanoscience and Nanotechnology, NCSR 'Demokritos', Athens, Greece) for the SEM characterization, Prof. Ariadne Argyraki, Dr Zacharenia Kypritidou and Mr Vassilis Skounakis (Department of Geology and Geosciences, NKUA, Athens, Greece) for the EDX and PXRD spectra, Dr Aikaterini Sakellari and Dr Sotirios Karavoltsos (Department of Chemistry, NKUA, Athens, Greece) for the AES data, and Prof. Eleni Efthimiadou (Department of Chemistry, NKUA, Athens, Greece) for the ATR-FTIR spectra. Finally, we are grateful to Covestro $\mathrm{AG}$ for kindly providing samples of Desmodur RE.

\section{References}

1 S. S. Kistler, Nature, 1931, 127, 741.

2 N. Leventis, A. Sadekar, N. Chandrasekaran and C. SotiriouLeventis, Chem. Mater., 2010, 22, 2790-2803.

3 J. P. Vareda, A. Lamy-Mendes and L. Durães, Microporous Mesoporous Mater., 2018, 258, 211-216.

4 M. A. Aegerter, N. Leventis and M. M. Koebel, Aerogels Handbook, Springer Science \& Business Media, 2011.

5 C. J. Stepanian, G. L. Gould and R. Begag, US Pat., US7078359 B2, 2006.

6 A. Arenillas, J. A. Menéndez, G. Reichenauer, A. Celzard, V. Fierro, F. J. Maldonado Hodar, E. Bailon-Garcia and N. Job, Properties of Carbon Aerogels and Their Organic Precursors, in Organic and Carbon Gels: From Laboratory Synthesis to Applications, ed. M. A. Aegerter and M. Prassas, Springer International Publishing, Cham, 2019, pp. 87-121.

7 R. W. Pekala, C. T. Alviso, F. M. Kong and S. S. Hulsey, J. Non-Cryst. Solids, 1992, 145, 90-98.

8 H. M. Far, S. Donthula, T. Taghvaee, A. M. Saeed, Z. Garr, C. Sotiriou-Leventis and N. Leventis, RSC Adv., 2017, 7, 51104-51120.

9 S. Mahadik-Khanolkar, S. Donthula, C. Sotiriou-Leventis and N. Leventis, Chem. Mater., 2014, 26, 1303-1317.

10 N. Leventis, C. Sotiriou-Leventis, N. Chandrasekaran, S. Mulik, Z. J. Larimore, H. Lu, G. Churu and J. T. Mang, Chem. Mater., 2010, 22, 6692-6710.

11 W. Rhine, J. Wang and R. Begag, US Pat., US7074880B2, 2006.

12 C. Chidambareswarapattar, Z. Larimore, C. SotiriouLeventis, J. T. Mang and N. Leventis, J. Mater. Chem., 2010, 20, 9666.

13 A. M. Saeed, P. M. Rewatkar, H. Majedi Far, T. Taghvaee, S. Donthula, C. Mandal, C. Sotiriou-Leventis and N. Leventis, ACS Appl. Mater. Interfaces, 2017, 9, 13520-13536.

14 A. M. Saeed, C. A. Wisner, S. Donthula, H. Majedi Far, C. Sotiriou-Leventis and N. Leventis, Chem. Mater., 2016, 28, 4867-4877.

15 A. G. Sadekar, S. S. Mahadik, A. N. Bang, Z. J. Larimore, C. A. Wisner, M. F. Bertino, A. K. Kalkan, J. T. Mang, C. Sotiriou-Leventis and N. Leventis, Chem. Mater., 2012, 24, 26-47. 
16 Z. Zhai, B. Ren, Y. Xu and Z. Liu, IOP Conf. Ser. Mater. Sci. Eng., 2019, 592, 012077.

17 Y. Liu, J. Chen, Z. Liu, H. Xu, Z. Shi, Q. Yang, G.-H. Hu and C. Xiong, J. Colloid Interface Sci., 2020, 576, 119-126.

18 W. Niu, Z. Xiao, S. Wang, S. Zhai, L. Qin, Z. Zhao and Q. An, J. Alloys Compd., 2021, 853, 157123.

19 L. Liu, X. Yang, C. Lv, A. Zhu, X. Zhu, S. Guo, C. Chen and D. Yang, ACS Appl. Mater. Interfaces, 2016, 8, 7047-7053.

20 H.-B. Zhao, J.-B. Cheng and Y.-Z. Wang, J. Alloys Compd., 2018, 736, 71-79.

21 J. Shu, Q. Niu, N. Wang, J. Nie and G. Ma, Appl. Surf. Sci., 2019, 485, 520-528.

22 L. Liu, X. Xu, Y. Li, R. Su, Q. Li, W. Zhou, B. Gao and Q. Yue, Chem. Eng. J., 2020, 382, 122780.

23 Z. Zhai, B. Ren, Y. Xu, S. Wang, L. Zhang and Z. Liu, Org. Electron., 2019, 70, 246-251.

24 W. Chen, M. Luo, K. Yang and X. Zhou, Int. J. Biol. Macromol., 2020, 158, 265-274.

25 Y. Hu, X. Tong, H. Zhuo, L. Zhong, X. Peng, S. Wang and R. Sun, RSC Adv., 2016, 6, 15788-15795.

26 P. Hao, Z. Zhao, Y. Leng, J. Tian, Y. Sang, R. I. Boughton, C. P. Wong, H. Liu and B. Yang, Nano Energy, 2015, 15, 9-23.

27 X. Liu, I. S. Amiinu, S. Liu, K. Cheng and S. Mu, Nanoscale, 2016, 8, 13311-13320.

28 M. A. Worsley, S. O. Kucheyev, J. H. Satcher, A. V. Hamza and T. F. Baumann, Appl. Phys. Lett., 2009, 94, 073115.

29 M. A. Worsley, P. J. Pauzauskie, T. Y. Olson, J. Biener, J. H. Satcher and T. F. Baumann, J. Am. Chem. Soc., 2010, 132, 14067-14069.

30 J. Liang, Z. Cai, L. Li, L. Guo and J. Geng, $R S C A d v .$, 2014, 4, 4843-4847.

31 Q. Luo, H. Zheng, Y. Hu, H. Zhuo, Z. Chen, X. Peng and L. Zhong, Ind. Eng. Chem. Res., 2019, 58, 17768-17775.

32 P. Paraskevopoulou, I. Smirnova, T. Athamneh, M. Papastergiou, D. Chriti, G. Mali, T. Čendak, M. Chatzichristidi, G. Raptopoulos and P. Gurikov, ACS Appl. Polym. Mater., 2020, 2, 1974-1988.

33 P. Paraskevopoulou, I. Smirnova, T. Athamneh, M. Papastergiou, D. Chriti, G. Mali, T. Čendak, G. Raptopoulos and P. Gurikov, RSC Adv., 2020, 10, 40843.

34 N. Leventis, Acc. Chem. Res., 2007, 40, 874-884.

35 N. Leventis, C. Sotiriou-Leventis, G. Zhang and A.-M. M. Rawashdeh, Nano Lett., 2002, 2, 957-960.

36 G. Zhang, A. Dass, A.-M. M. Rawashdeh, J. Thomas, J. A. Counsil, C. Sotiriou-Leventis, E. F. Fabrizio, F. Ilhan, P. Vassilaras, D. A. Scheiman, L. McCorkle, A. Palczer, J. C. Johnston, M. A. Meador and N. Leventis, J. Non-Cryst. Solids, 2004, 350, 152-164.

37 C. Mandal, S. Donthula, H. M. Far, A. M. Saeed, C. SotiriouLeventis and N. Leventis, J. Sol-Gel Sci. Technol., 2019, 92, 84-100.

38 N. Leventis, N. Chandrasekaran, A. G. Sadekar, C. Sotiriou-Leventis and H. Lu, J. Am. Chem. Soc., 2009, 131, 4576-4577.

39 N. Leventis, P. Vassilaras, E. F. Fabrizio and A. Dass, J. Mater. Chem., 2007, 17, 1502-1508.
40 P. M. Rewatkar, R. U. Soni, C. Sotiriou-Leventis and N. Leventis, ACS Appl. Mater. Interfaces, 2019, 11, 22668-22676.

41 H. Luo, G. Churu, E. F. Fabrizio, J. Schnobrich, A. Hobbs, A. Dass, S. Mulik, Y. Zhang, B. P. Grady, A. Capecelatro, C. Sotiriou-Leventis, H. Lu and N. Leventis, J. Sol-Gel Sci. Technol., 2008, 48, 113-134.

42 N. Leventis, C. Sotiriou-Leventis, S. Mulik, A. Dass, J. Schnobrich, A. Hobbs, E. F. Fabrizio, H. Luo, G. Churu, Y. Zhang and H. Lu, J. Mater. Chem., 2008, 18, 2475-2482.

43 P. M. Rewatkar, T. Taghvaee, A. M. Saeed, S. Donthula, C. Mandal, N. Chandrasekaran, T. Leventis, T. K. Shruthi, C. Sotiriou-Leventis and N. Leventis, Chem. Mater., 2018, 30, 1635-1647.

44 I. Smirnova and P. Gurikov, Annu. Rev. Chem. Biomol. Eng., 2017, 8, 307-334.

45 R. Subrahmanyam, P. Gurikov, P. Dieringer, M. Sun and I. Smirnova, Gels, 2015, 1, 291-313.

46 M. Papastergiou, A. Kanellou, D. Chriti, G. Raptopoulos and P. Paraskevopoulou, Materials, 2018, 11, 2249.

47 S. H. Ching, N. Bansal and B. Bhandari, Crit. Rev. Food Sci. Nutr., 2017, 57, 1133-1152.

48 S. S. Kistler, J. Phys. Chem., 1931, 36, 52-64.

49 P. Paraskevopoulou, P. Gurikov, G. Raptopoulos, D. Chriti, M. Papastergiou, Z. Kypritidou, V. Skounakis and A. Argyraki, Polyhedron, 2018, 154, 209-216.

50 D. Filipiuk, L. Fuks and M. Majdan, J. Mol. Struct., 2005, 744-747, 705-709.

51 S. K. Papageorgiou, E. P. Kouvelos, E. P. Favvas, A. A. Sapalidis, G. E. Romanos and F. K. Katsaros, Carbohydr. Res., 2010, 345, 469-473.

52 N. Leventis, C. Sotiriou-Leventis, A. M. Saeed, S. Donthula, H. Majedi Far, P. M. Rewatkar, H. Kaiser, J. D. Robertson, H. Lu and G. Churu, Chem. Mater., 2016, 28, 67-78.

53 J. S. Rowbotham, P. W. Dyer, H. C. Greenwell, D. Selby and M. K. Theodorou, Interface Focus, 2013, 3, 20120046.

54 T. S. Pathak, J. S. Kim, S.-J. Lee, D.-J. Baek and K.-J. Paeng, J. Polym. Environ., 2008, 16, 198-204.

55 A. B. Ross, C. Hall, K. Anastasakis, A. Westwood, J. M. Jones and R. J. Crewe, J. Anal. Appl. Pyrolysis, 2011, 91, 344-351.

56 A. Kanellou, G. C. Anyfantis, D. Chriti, G. Raptopoulos, M. Pitsikalis and P. Paraskevopoulou, Molecules, 2018, 23, 1007.

57 C. Chidambareswarapattar, P. M. McCarver, H. Luo, H. Lu, C. Sotiriou-Leventis and N. Leventis, Chem. Mater., 2013, 25, 3205-3224.

58 A. Bang, C. Buback, C. Sotiriou-Leventis and N. Leventis, Chem. Mater., 2014, 26, 6979-6993.

59 D. Chriti, G. Raptopoulos, M. Papastergiou and P. Paraskevopoulou, Gels, 2018, 4, 66.

60 M. Robitzer, L. David, C. Rochas, F. D. Renzo and F. Quignard, Macromol. Symp., 2008, 273, 80-84.

61 N. N. Greenwood and A. Earnshaw, Chemistry of the Elements, Elsevier, 2012.

62 A. L. Patterson, Phys. Rev., 1939, 56, 978-982.

63 O. C. Compton and S. T. Nguyen, Small, 2010, 6, 711-723.

64 W. Zhao, G. Kido, K. Hara and H. Noguchi, J. Electroanal. Chem., 2014, 712, 185-193. 
65 L. G. Cançado, K. Takai, T. Enoki, M. Endo, Y. A. Kim, H. Mizusaki, A. Jorio, L. N. Coelho, R. Magalhães-Paniago and M. A. Pimenta, Appl. Phys. Lett., 2006, 88, 163106.

66 M. Athanasiou, N. Samartzis, L. Sygellou, V. Dracopoulos, T. Ioannides and S. N. Yannopoulos, Carbon, 2021, 172, 750-761.

67 E. Raymundo-Piñero, F. Leroux and F. Béguin, Adv. Mater., 2006, 18, 1877-1882.

68 C. Bosch-Navarro, F. Busolo, E. Coronado, Y. Duan, C. Martí-Gastaldo and H. Prima-Garcia, J. Mater. Chem. C, 2013, 1, 4590-4598.

69 N. S. Mcintyre and M. G. Cook, Anal. Chem., 1975, 47, 2208-2213.

70 C. M. Kim, H. S. Jeong and E. H. Kim, Surf. Sci., 2000, 459, L457-L461.

71 L. Q. Wu, S. Q. Li, Y. C. Li, Z. Z. Li, G. D. Tang, W. H. Qi, L. C. Xue, L. L. Ding and X. S. Ge, Appl. Phys. Lett., 2016, 108, 021905.
72 D. Briggs and G. Beamson, Anal. Chem., 1993, 65, 1517-1523.

73 G. P. López, D. G. Castner and B. D. Ratner, Surf. Interface Anal., 1991, 17, 267-272.

74 M. Lawrinenko and D. A. Laird, Green Chem., 2015, 17, 4628-4636.

75 H. M. Far, P. M. Rewatkar, S. Donthula, T. Taghvaee, A. M. Saeed, C. Sotiriou-Leventis and N. Leventis, Macromol. Chem. Phys., 2019, 220, 1800333.

76 M. Inagaki, M. Toyoda, Y. Soneda and T. Morishita, Carbon, 2018, 132, 104-140.

77 A. T. Balaban, G. D. Mateescu and M. Elian, Tetrahedron, 1962, 18, 1083-1094.

78 M. P. Kumar, T. Kesavan, G. Kalita, P. Ragupathy, T. N. Narayanan and D. K. Pattanayak, RSC Adv., 2014, 4, 38689-38697.

79 P. A. Webb and C. Orr, Analytical Methods in Fine Particle Technology, Micromeritics Instrument Corporation, Norcross, GA, 1997. 